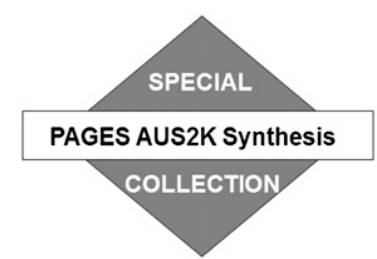

\title{
Paleoclimate Data-Model Comparison and the Role of Climate Forcings over the Past 1500 Years*
}

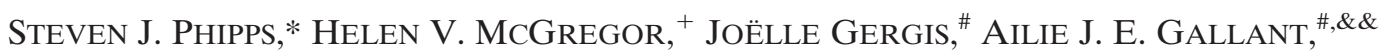 \\ RAPHAEl NEUKOM, ${ }^{@}$ SAMANTHA STEVENSON, ${ }^{\&}$ DUNCAN ACKERLEY,** \\ JOSEPHINE R. BROWN, ${ }^{++}$MATT J. FISCHER, ${ }^{\# \#}$ AND TAS D. VAN OMMEN ${ }^{@ @ ~}$ \\ * Climate Change Research Centre, and ARC Centre of Excellence for Climate System Science, University of New South Wales, \\ Sydney, New South Wales, Australia \\ ${ }^{+}$School of Earth and Environmental Sciences, University of Wollongong, Wollongong, New South Wales, Australia \\ " School of Earth Sciences, University of Melbourne, Parkville, Victoria, Australia \\ ${ }^{\circledR}$ Swiss Federal Research Institute WSL, Birmensdorf, and Oeschger Centre for Climate Change Research, \\ University of Bern, Bern, Switzerland \\ ${ }^{\&}$ International Pacific Research Center, University of Hawai'i at Mānoa, Honolulu, Hawaii \\ ** Monash Weather and Climate, Monash University, Clayton, Victoria, Australia \\ ${ }^{++}$Centre for Australian Weather and Climate Research, Melbourne, Victoria, Australia \\ \#\# Institute for Environmental Research, Australian Nuclear Science and Technology Organisation, Menai, New South Wales, Australia \\ ${ }^{@ @ A u s t r a l i a n}$ Antarctic Division, Kingston, and Antarctic Climate \& Ecosystems CRC, University of Tasmania, Hobart, Tasmania, Australia
}

(Manuscript received 8 February 2012, in final form 31 January 2013)

\begin{abstract}
The past 1500 years provide a valuable opportunity to study the response of the climate system to external forcings. However, the integration of paleoclimate proxies with climate modeling is critical to improving the understanding of climate dynamics. In this paper, a climate system model and proxy records are therefore used to study the role of natural and anthropogenic forcings in driving the global climate. The inverse and forward approaches to paleoclimate data-model comparison are applied, and sources of uncertainty are identified and discussed. In the first of two case studies, the climate model simulations are compared with multiproxy temperature reconstructions. Robust solar and volcanic signals are detected in Southern Hemisphere temperatures, with a possible volcanic signal detected in the Northern Hemisphere. The anthropogenic signal dominates during the industrial period. It is also found that seasonal and geographical biases may cause multiproxy reconstructions to overestimate the magnitude of the long-term preindustrial cooling trend. In the second case study, the model simulations are compared with a coral $\delta^{18} \mathrm{O}$ record from the central Pacific Ocean. It is found that greenhouse gases, solar irradiance, and volcanic eruptions all influence the mean state of the central Pacific, but there is no evidence that natural or anthropogenic forcings have any systematic impact on El Niño-Southern Oscillation. The proxy climate relationship is found to change over time, challenging the assumption of stationarity that underlies the interpretation of paleoclimate proxies. These case studies demonstrate the value of paleoclimate data-model comparison but also highlight the limitations of current techniques and demonstrate the need to develop alternative approaches.
\end{abstract}

\footnotetext{
* International Pacific Research Center/School of Ocean and Earth Science and Technology Publication Number 983/8935.

\&\& Current affiliation: School of Geography and Environmental Science, Monash University, Victoria, Australia.
}

Corresponding author address: Steven J. Phipps, Climate Change Research Centre, University of New South Wales, UNSW Sydney, NSW 2052, Australia.

E-mail: s.phipps@unsw.edu.au

\section{Introduction}

\section{a. The climate of the past 1500 years}

The past 1500 years have been characterized by significant changes in the global climate (e.g., Jansen et al. 2007; Jones et al. 2009; Mann et al. 2009; Diaz et al. 2011; Graham et al. 2011). The Northern Hemisphere (NH) experienced a relatively warm period known as the Medieval Climate Anomaly [MCA; 950-1250 CE (Common 
Era)], during which the hemispheric-scale temperature was similar to twentieth-century levels. This was followed by a relatively cool period known as the Little Ice Age (LIA; 1400-1700 CE). The LIA persisted until the start of the industrial period and was followed by rapid increases in temperature during the twentieth century (Trenberth et al. 2007). Changes in the Southern Hemisphere (SH) climate are less well understood but, on the hemispheric scale at least, appear to have exhibited similar warm and cool periods (Jansen et al. 2007; Mann et al. 2008).

There is strong evidence that natural forcings drove changes in the global climate over this period. Orbitally driven changes in insolation were small on the global scale but could be significant on the regional scale. For example, the long-term preindustrial cooling trend at high northern latitudes can be attributed to orbital forcing (Kaufman et al. 2009; Esper et al. 2012). Changes in solar irradiance may have been globally significant, particularly the reductions in irradiance during solar grand minima (Steinhilber et al. 2012). The 1645-1715 CE Maunder Minimum, for example, is likely to have contributed toward the cool conditions during the LIA (Shindell et al. 2001). Volcanic eruptions produce strong cooling events that typically last several years (e.g., Thompson et al. 2009) but can also be important on longer time scales. In particular, a succession of major eruptions during the thirteenth century has been identified as the trigger for the onset of the LIA (Miller et al. 2012). Since the nineteenth century, other forcings have become increasingly important with a detectable anthropogenic influence on the twentieth-century climate (Hegerl et al. 2007b).

The past 1500 years therefore provide a valuable opportunity to study the response of the global climate to external forcings. Significant changes have taken place within the climate system over this period, and proxy data that record these changes cover a wide geographical area and have high temporal resolution (e.g., Mann et al. 2008). Natural and anthropogenic forcings are also reasonably well constrained (e.g., Schmidt et al. 2012). With knowledge of changes in the global climate and the potential external drivers, this period is well suited to a combined data-modeling approach to understanding the response of the climate system to external forcings (e.g., Fernández-Donado et al. 2013).

However, despite the quantity and quality of the available data, our understanding of the events of the past 1500 years and their origins remains limited. The cause of the MCA is unclear, with climate models unable to reproduce the reconstructed warmth of this period (e.g., Mann et al. 2009; Fernández-Donado et al. 2013). When combined with proxy evidence, this suggests that the MCA may have arisen from an internal reorganization of the climate system (Diaz et al. 2011; Graham et al. 2011). While detection and attribution studies have found a significant role of volcanic eruptions in driving the preindustrial Northern Hemisphere climate, the availability of proxy data has restricted these studies to the extratropics and/or periods shorter than 1000 years (Hegerl et al. 2003, 2007a). Thus our knowledge of the role of climate forcings over the past 1500 years remains limited, particularly for regions that lie outside the northern extratropics.

\section{b. Paleoclimate data-model comparison}

Paleoclimate proxies and climate models constitute two contrasting and yet complementary sources of information on past climates. Both approaches can be applied independently of the other to generate insights into the dynamics of the climate system. For example, both proxy data (e.g., Tudhope et al. 2001; Moy et al. 2002; Cobb et al. 2003) and climate modeling (e.g., Liu et al. 2000; OttoBliesner et al. 2006; Zheng et al. 2008) have been applied to study past changes in the dynamics of El Niño-Southern Oscillation (ENSO). However, more information can be extracted about the drivers of climate variability and change when the two approaches are combined. Proxy data can be used to constrain and evaluate model simulations, while climate models can be used to explore the mechanisms that have driven past climatic changes. For example, Mann et al. (2009), Graham et al. (2011), and Goosse et al. (2012) combine proxy data with climate modeling to study the dynamical origins of the MCA.

Paleoclimate data-model comparison can be used to assess model performance (e.g., Braconnot et al. 2007a,b), to constrain projections of future climate change (e.g., Hargreaves and Annan 2009), or to study the drivers of climate variability and change (e.g., Hegerl et al. 2007a). From a quantitative perspective, the primary limitation to data-model comparison is the fact that paleoclimate proxies and climate models generate different sets of variables. Models directly simulate physical variables such as temperature or precipitation, whereas proxies typically provide chemical or biophysical variables such as $\delta^{18} \mathrm{O}$ or tree ring width. These variables are not directly comparable. There are two basic classes of technique that have been developed over time to address this fundamental incompatibility (e.g., Bartlein et al. 1998): 1) the inverse approach, which seeks to translate proxy variables into the physical variables simulated by models, and 2) the forward approach, which seeks to translate model variables into proxy variables.

\section{1) INVERSE APPROACH}

Paleoclimate proxy variables can be converted into physical climate variables by using instrumental data to establish an empirical relationship. Statistical techniques 
such as linear regression are used to calibrate a proxy variable at a particular location against local or remote climatic variables. Examples include the calibration of coral $\mathrm{Sr} / \mathrm{Ca}$ and $\delta^{18} \mathrm{O}$ against local sea surface temperature (e.g., Corrège 2006) or the calibration of ice core accumulation in Antarctica against precipitation in southwest Western Australia (van Ommen and Morgan 2010). Multiproxy networks comprise data from multiple archives and multiple sites. Such networks are used to reconstruct climatic variables from the regional to global scale, generating spatial averages (e.g., Mann et al. 2008), gridded spatial fields (e.g., Mann et al. 2009), or indices of largescale modes of variability such as El Niño-Southern Oscillation (e.g., Wilson et al. 2010).

However, inverse techniques suffer from a number of limitations. The most critical of these is the necessary but usually implicit assumption of stationarity. Modern instrumental observations are used to calibrate proxy variables against climatic variables, with these relationships then assumed to have applied invariantly in the past. There is no a priori reason to believe that this assumption is valid, and this therefore represents a source of uncertainty that is potentially large and difficult to quantify. A second limitation is the fact that proxies can integrate multiple environmental variables (e.g., Gagan et al. 2000; Fischer and Treble 2008). As a result, changes in proxy variables often cannot be translated into changes in any single climatic variable without a loss of information. Finally, the statistical techniques used to generate multiproxy reconstructions can also contribute uncertainty, although this is at least quantifiable (Frank et al. 2010; Gergis et al. 2012; Wahl and Smerdon 2012).

Paleoclimate data assimilation is a process whereby proxy data are incorporated into a computer model (e.g., Goosse et al. 2012). This requires that proxy variables first be converted into the physical variables simulated by the model, and paleoclimate data assimilation can therefore be regarded as an application of the inverse approach.

\section{2) FORWARD APPROACH}

Forward models use physical and biological principles to directly simulate the evolution of proxy variables within a climate modeling framework (e.g., TolwinskiWard et al. 2011; Baker et al. 2012). This approach has two crucial advantages over inverse techniques. First, by allowing the relationships between proxies and climatic variables to evolve over time, forward modeling is the only approach that is capable of avoiding the assumption of stationarity. Second, by incorporating mechanistic descriptions of the processes that determine the evolution of proxy variables, forward modeling can account for the fact that proxies integrate multiple environmental variables. Examples of forward models developed to date include those that describe tree ring width (Evans et al. 2006; Tolwinski-Ward et al. 2011), tree ring $\delta^{18} \mathrm{O}$ (Evans 2007; Berkelhammer and Stott 2009), coral $\delta^{18} \mathrm{O}$ (Brown et al. 2006; Tindall et al. 2009), and speleothem $\delta^{18} \mathrm{O}$ (Baker et al. 2012).

Forward models can be characterized in terms of their completeness and the extent to which they integrate different processes, exactly as for climate models (Claussen et al. 2002). At one extreme, forward models will incorporate a complete description of all the physical and biological processes that describe the evolution of a proxy variable. Arguably no such model currently exists, but forward models such as those of Evans et al. (2006), Evans (2007), and Baker et al. (2012) all succeed in integrating descriptions of multiple processes. At the other extreme, forward models can be simple, linear, and parameterized. An example is the pseudocoral approach, which seeks to describe the evolution of coral $\delta^{18} \mathrm{O}$ in terms of nonisotopic climate variables (Brown et al. 2008; Thompson et al. 2011). Linear regression is used to derive empirical calibrations for such models, based on either observational or climate model data. Although this introduces the assumption of stationarity in proxy climate relationships, pseudocorals and related approaches will have value as a tool for data-model comparison until such time as isotope-enabled climate models become commonplace.

Despite the promise of forward modeling, it will ultimately require that complete and accurate process models be developed for each proxy. Furthermore, such models will only be able to simulate proxy variables correctly if they are embedded within climate modeling frameworks that supply them with accurate environmental variables. Until such time as these criteria are fulfilled, forward modeling may be no better than other approaches to paleoclimate data-model comparison.

\section{c. This study}

In this paper, we use paleoclimate data-model comparison to study the role of natural and anthropogenic forcings in driving the global climate over the past 1500 years. A fast global climate model is used to conduct multiple new simulations of this period, with different combinations of forcings being applied. Two complementary approaches are employed to compare the model simulations with a variety of paleoclimate datasets. Throughout, sources of uncertainty are identified and discussed.

The climate model simulations and paleoclimate datasets used are described in section 2 . In section 3, the inverse approach to paleoclimate data-model comparison is used to compare the model simulations with two multiproxy temperature reconstructions. We seek to identify the drivers of hemispheric-scale temperature, 
building upon existing studies of the Northern Hemisphere and extending them to assess the drivers of past changes in the Southern Hemisphere. In section 4, the forward approach is then used to compare the model simulations with a coral $\delta^{18} \mathrm{O}$ record from the central Pacific Ocean. We build upon previous work in developing simple forward models of coral isotopes, constructing a pseudocoral that is capable of describing multiple climatic influences on the ENSO signal in coral $\delta^{18} \mathrm{O}$. We then use this indicator to assess the influences of natural and anthropogenic forcings on the mean state of the central Pacific and on ENSO variability. Finally, section 5 discusses the results, presents conclusions, and suggests future priorities for paleoclimate research.

\section{Data and methods}

\section{a. Climate model simulations}

This study uses the Commonwealth Scientific and Industrial Research Organisation Mark 3L (CSIRO Mk3L) climate system model, version 1.2, which features enhanced spatial resolution in the ocean relative to the original release of the model (Phipps et al. 2011, 2012). Mk3L is a fully coupled general circulation model that includes components describing the atmosphere, ocean, sea ice, and land surface. Version 1.2 uses horizontal resolutions of $5.6^{\circ}$ longitude by $3.2^{\circ}$ latitude for the atmosphere, sea ice, and land surface models and $2.8^{\circ}$ longitude by $1.6^{\circ}$ latitude for the ocean model. There are 18 vertical levels in the atmosphere and 21 in the ocean.

Mk3L produces a realistic simulation of the modern climate (Phipps et al. 2011) and has utility for studying the response of the climate system to both natural and anthropogenic forcings (Phipps and Brown 2010; Phipps et al. 2012). Flux adjustments with a fixed annual cycle are used to minimize drift and to improve the realism of the simulated climate. The spatial and temporal variability associated with ENSO is represented reasonably well, although the simulated variability has a slightly longer periodicity relative to observations (Santoso et al. 2011). Mk3L does not include biophysical components such as a dynamic vegetation model or representations of the global carbon cycle. Neither does it include any simulation of stable isotopes such as ${ }^{18} \mathrm{O}$. However, the relative simplicity of the model compared to some stateof-the-art Earth system models combined with its relatively coarse spatial resolution generates a model that is extremely computationally efficient. This allows it to be used here to conduct multiple ensembles of simulations spanning the past 1500 years.

Four different natural and anthropogenic forcings are applied to the model. Changes in Earth's orbital parameters are calculated using the method of Berger (1978), while concentrations of anthropogenic greenhouse gases are from MacFarling Meure et al. (2006). Total solar irradiance is from Steinhilber et al. (2009), and the stratospheric sulfate aerosols arising from volcanic eruptions are from the Ice Core Volcanic Index 2 of Gao et al. (2008). The method described by Phipps et al. (2012) is used to convert the stratospheric sulfate aerosol loading into an equivalent perturbation to the total solar irradiance. Figure 1 shows the variations in each of these climate forcings over the past 1500 years.

Four ensembles of climate model simulations are studied here. Different combinations of forcings are applied, as summarized and expanded in Table 1. Each ensemble consists of three independent simulations. The model was first initialized from a preindustrial control simulation and was then run to equilibrium under permanent $1 \mathrm{CE}$ boundary conditions. The individual members of ensembles $\mathrm{O}, \mathrm{OG}$, and OGS were initialized from different years of this simulation and run for 2000 years. The members of ensemble OGSV were initialized from the state of each member of ensemble OGS at the end of year $500 \mathrm{CE}$; they could not be initialized earlier, as the volcanic forcing dataset used to drive the model only covers the period from $501 \mathrm{CE}$ onward.

Thus, the members of each ensemble differ only in the initial conditions, with the model physics and the boundary conditions being identical. The differences between each ensemble are therefore due to external forcings, while the differences within each ensemble are due to unforced internal variability. Using ensemble averages reduces the influence of internal variability when studying the response of the climate system to external forcings.

\section{b. Temperature reconstructions}

Two state-of-the-art multiproxy hemispheric temperature reconstructions are chosen as the basis for the first case study. The Northern and Southern Hemisphere reconstructions of Mann et al. (2008) were derived from a global network of 1209 annually and decadally resolved proxies. The data were obtained from archives that include ice cores, coral, speleothems, and sediments; however, tree rings dominate, providing 1032 $(85 \%)$ of the records used. The majority of the proxies (1036, of which $86 \%$ are derived from tree rings) are located in the Northern Hemisphere, while 173 (of which $83 \%$ are derived from tree rings) are located in the Southern Hemisphere. The proxy network was calibrated against combined land and ocean Hadley Centre Climatic Research Unit, version 3 (HadCRUT3v) annualmean temperature data (Brohan et al. 2006; Rayner et al. 2006) for the period 1850-2006 CE. A version of the "error in variables" method (EIV or "total least squares"; 
(a) Insolation (2000 CE minus $500 \mathrm{CE}, \mathrm{Wm}^{-2}$ )

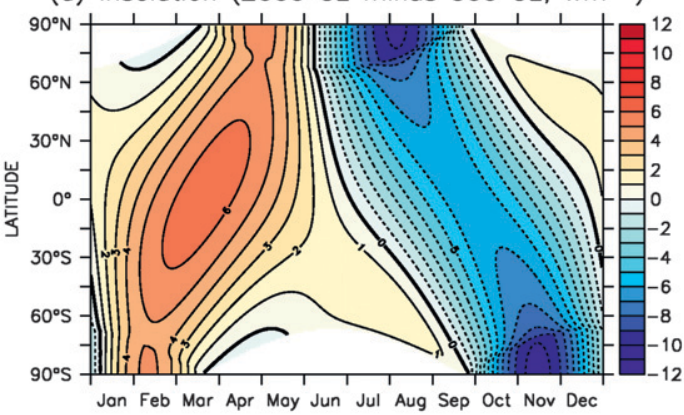

(c) Total solar irradiance

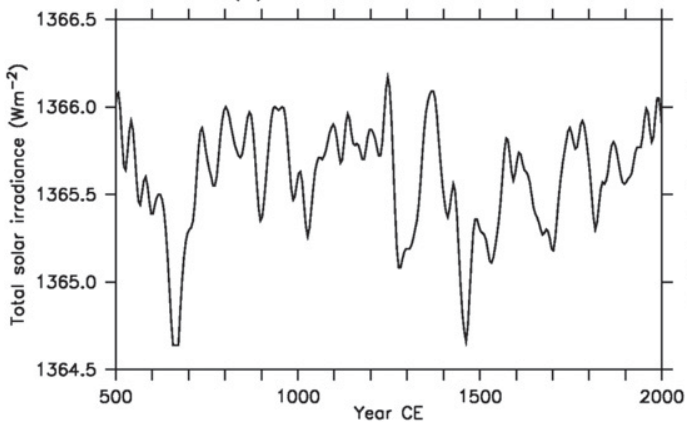

(b) Equivalent $\mathrm{CO}_{2}$ concentration

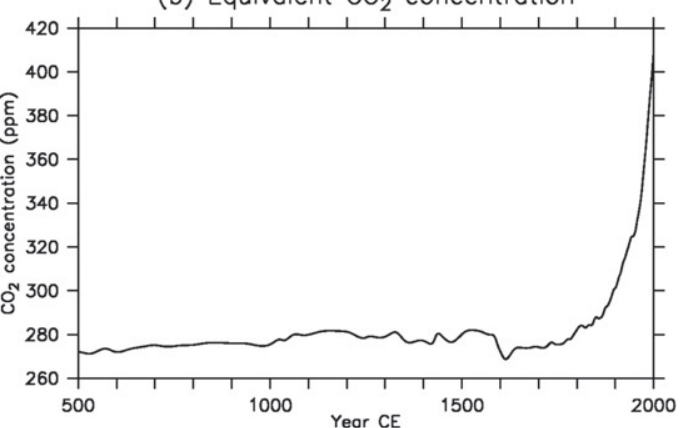

(d) Radiative forcing due to volcanoes

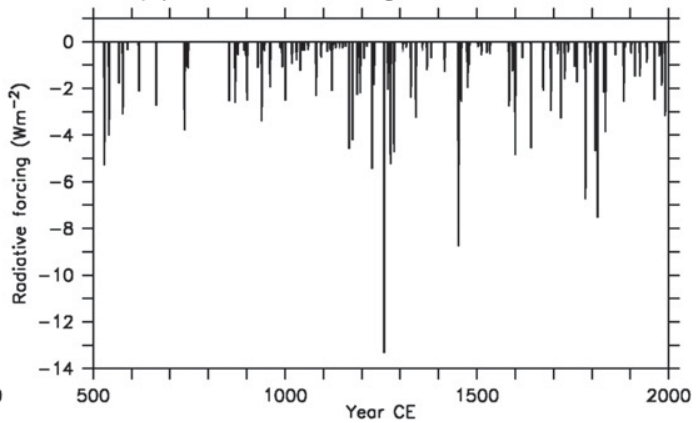

FIG. 1. The forcings on the climate system between 500 and $2000 \mathrm{CE}$ : (a) the changes in the distribution of insolation due to changes in Earth's orbital geometry, (b) the equivalent $\mathrm{CO}_{2}$ concentration (MacFarling Meure et al. 2006), (c) total solar irradiance (Steinhilber et al. 2009), and (d) the radiative forcing due to volcanic eruptions (Gao et al. 2008).

Hegerl et al. 2007a) based on the regularized expectationmaximization algorithm (RegEM; Schneider 2001) was used to regress the proxies against the instrumental target. Hemispheric-mean surface air temperature was reconstructed for the Northern Hemisphere for the period 300-2006 CE and for the Southern Hemisphere for the period 400-2006 CE. A decadal filter was applied to the final reconstructions, to reflect the temporal resolution of the proxies from which they were derived.

\section{c. Coral $\delta^{18} \mathrm{O}$}

The proxy dataset used as the basis for the second case study is the coral $\delta^{18} \mathrm{O}$ record from Palmyra Island $\left(6^{\circ} \mathrm{N}\right.$, $162^{\circ} \mathrm{W}$ ) in the central Pacific Ocean (Cobb et al. 2003). This record is chosen for a number of reasons. First, as Palmyra Island lies in the tropics and only just outside the Niño-3.4 region $\left(5^{\circ} \mathrm{S}-5^{\circ} \mathrm{N}, 170^{\circ}-120^{\circ} \mathrm{W}\right)$, the local climate is dominated by ENSO. El Niño events bring warm wet conditions and negative coral $\delta^{18} \mathrm{O}$ anomalies, while $\mathrm{La}$ Niña events bring cool dry conditions and positive coral $\delta^{18} \mathrm{O}$ anomalies (Cobb et al. 2003). Second, it provides a record of ENSO variability spanning the last 1100 years, albeit a discontinuous one. Finally, analysis of the record by Cobb et al. (2003) reveals evidence of rapid shifts in ENSO amplitude and frequency. These regime changes appear to be uncorrelated with either external forcings or the mean state of the climate, suggesting that variability arises from within the internal dynamics of the ENSO system itself (Jin et al. 1994; Tziperman et al. 1994). The climate model simulations presented here provide an opportunity to test this conclusion.

\section{Drivers of hemispheric-scale temperature}

In this section, we study the role of natural and anthropogenic forcings in driving temperature at the hemispheric scale. The climate model simulations are compared with the two multiproxy temperature reconstructions (section 2b). CSIRO Mk3L is particularly advantageous for a study of this nature, as it allows us to conduct multiple

TABLE 1. A summary of the forcings applied in the four ensembles of climate model simulations presented herein.

\begin{tabular}{ll}
\hline \hline Ensemble & \multicolumn{1}{c}{ Forcing(s) } \\
\hline O & Orbital \\
OG & Orbital, greenhouse gases \\
OGS & Orbital, greenhouse gases, solar irradiance \\
OGSV & Orbital, greenhouse gases, solar irradiance, \\
& volcanic aerosols \\
\hline
\end{tabular}


ensembles of simulations using different combinations of forcings. The Northern Hemisphere is studied first, allowing a comparison with previous work. The analysis is then extended to the Southern Hemisphere, before exploring the role of orbital forcing in driving the longterm preindustrial cooling trend seen in both reconstructions. By comparing the model simulations with multiproxy temperature reconstructions, the analysis in this section represents an application of the inverse approach to paleoclimate data-model comparison (section 1b).

A number of previous studies have used climate model simulations to detect natural and anthropogenic signals in reconstructions of regional or hemisphericscale temperature (Free and Robock 1999; Crowley 2000; Hegerl et al. 2003, 2007a, 2011). These studies have employed statistical techniques ranging from correlation-based approaches to the application of optimal fingerprinting (Allen and Stott 2003; Stott et al. 2003). This latter technique has been widely used to detect and attribute anthropogenic influences on the global climate (e.g., Hegerl et al. 2007b). Over relatively short periods such as the twentieth century, the "fingerprints" derived from climate model simulations must incorporate spatial information in order to adequately distinguish between the responses to different external forcings (Hegerl et al. 2007b). On longer time scales, however, the evolutions of each forcing over time are sufficiently different that the fingerprints can be purely temporal (Hegerl et al. 2003, 2007a, 2011).

Here, we attempt to detect natural and anthropogenic signals in Northern and Southern Hemisphere temperature over the past 1500 years. To do this, we calculate the residuals between the model simulations and the reconstructions. If an individual forcing reduces the residual by an amount that is statistically significant at the $95 \%$ confidence level, we conclude that the forcing is a driver of hemispheric-mean temperature.

\section{a. Northern Hemisphere}

Figure 2 shows the simulated annual-mean Northern Hemisphere surface air temperature (SAT) for each ensemble of climate model simulations and compares it with the reconstruction of Mann et al. (2008). When orbital forcing alone is applied to the model (Fig. 2a), it exhibits weak internal variability on interdecadal time scales and no observable long-term trend. The addition of greenhouse gases (Fig. 2b) causes the model to reproduce the warming trend during the industrial period but has little impact prior to $1800 \mathrm{CE}$. When solar forcing is introduced (Fig. 2c), the model begins to simulate centennial-scale variability during the preindustrial era. The ensemble mean remains above the
1500-1850 CE average-albeit by less than $0.2 \mathrm{~K}$-for most of the period from 950 to $1300 \mathrm{CE}$, coincident with the MCA and a period of relatively high solar irradiance (Fig. 1c).

When volcanic forcing is introduced (Fig. 2d), the magnitude of the simulated interdecadal variability increases to a level similar to the reconstruction. Strong cooling in response to the Kuwae (1452 CE) and Tambora (1815 CE) eruptions is apparent in both the reconstruction and the model simulations. However, while the model simulates a decadal cooling of around $0.6 \mathrm{~K}$ in response to the eruption of $1258 \mathrm{CE}$ - the largest volcanic eruption of the past 1500 years (Gao et al. 2008) - no cooling signal is apparent in the reconstruction. Possible reasons for this discrepancy include deficiencies in the volcanic reconstruction used to force the model, deficiencies in the representation of volcanic aerosols within the model (Timmreck et al. 2009), or the fact that proxy networks that incorporate tree ring data can underestimate the cooling that follows large volcanic eruptions (Robock 2005; Mann et al. 2012). Nonetheless, when all forcings are applied, the model is consistent with the reconstruction from the early fifteenth century onward.

We now use the model simulations to assess the influence of each forcing on hemispheric-scale temperature. Table $2 \mathrm{a}$ shows the root-mean-square error (RMSE) in the mean of each model ensemble, calculated relative to the reconstruction. Over the full period (501-2000 $\mathrm{CE})$ the addition of volcanic forcing improves the agreement between the model and the reconstruction by a statistically significant amount: the RMSE for ensemble OGSV is $0.014 \pm 0.013 \mathrm{~K}$ smaller than that for ensemble OGS. However, within the framework employed here, we find no detectable influences of greenhouse gases or solar irradiance on the $\mathrm{NH}$ climate. In the case of greenhouse gases this is not surprising, as these are a minor forcing for the bulk of this period. For the preindustrial period (501-1850 CE) similar results are obtained. Only the influence of volcanic forcing is detectable, reducing the RMSE in ensemble OGSV by a narrowly significant $0.014 \pm 0.014 \mathrm{~K}$ relative to ensemble OGS. In contrast, over the industrial period (1851-2000 CE) a strong and significant influence of greenhouse gases is now apparent, but there are no detectable influences from either solar or volcanic forcings.

Thus, a picture emerges of a detectable but weak role of volcanic eruptions in driving the $\mathrm{NH}$ climate, with greenhouse gases becoming dominant during the industrial period. Previous studies that employed optimal fingerprinting have found robust volcanic and anthropogenic signals in reconstructions of $\mathrm{NH}$ climate but no consistent solar signal (Hegerl et al. 2003, 2007a). These studies were restricted to either the extratropics and/or 
(a) Orbital

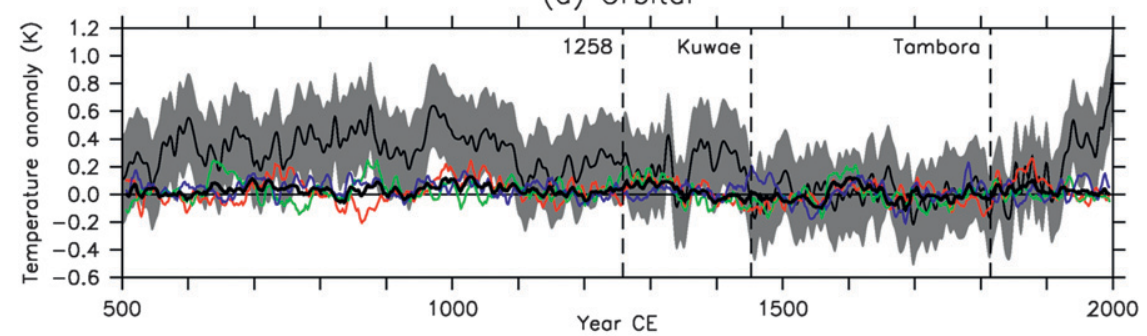

(b) Orbital-Greenhouse

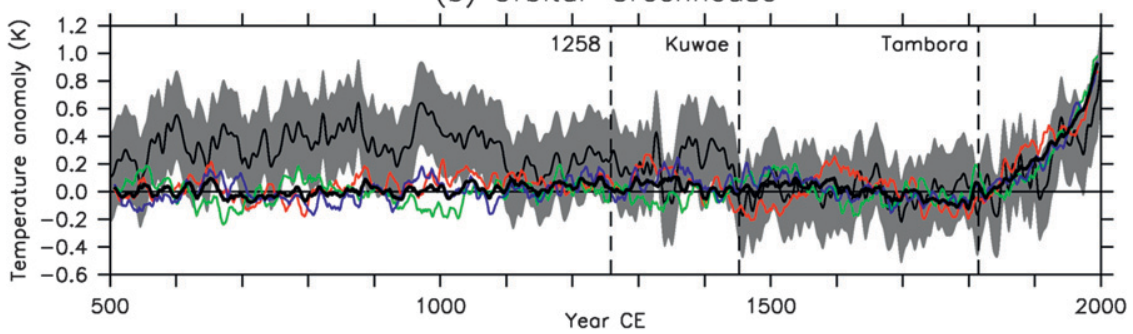

(c) Orbital-Greenhouse-Solar

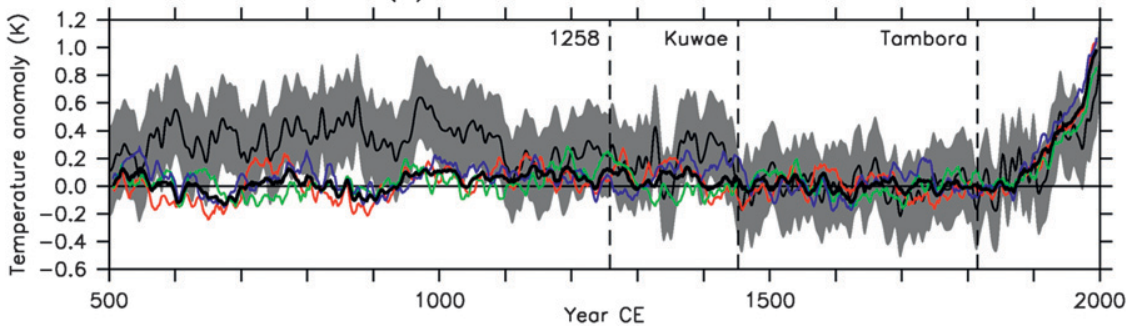

(d) Orbital-Greenhouse-Solar-Volcanic

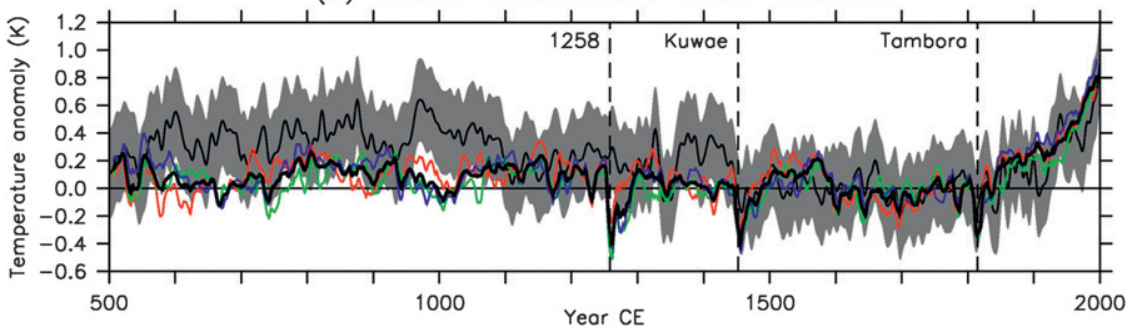

FIG. 2. The simulated annual-mean Northern Hemisphere surface air temperature for each ensemble of climate model simulations, compared with the reconstruction of Mann et al. (2008). The red, blue, and green lines show the 10-yr running means for individual simulations, and the thick black lines show the ensemble mean. The $95 \%$ confidence interval for Mann et al. (2008) is indicated by gray shading. All values are expressed as anomalies relative to the 1500 $1850 \mathrm{CE}$ mean. Vertical dashed lines indicate the volcanic eruptions of $1258 \mathrm{CE}$ (unknown location), 1452 CE (Kuwae), and 1815 CE (Tambora).

the last millennium because of the availability of proxy data and climate model simulations. Here, we have been able to reach similar conclusions and also show that they apply on the hemispheric scale over the past 1500 years.

However, we identify multiple sources of uncertainty. The agreement between the model and the reconstruction becomes increasingly poor prior to 1450 CE (Fig. 2d). This suggests either declining skill in the reconstruction or in the forcing datasets used to drive the model, or deficiencies in the model physics. All of these explanations are plausible. The reconstruction becomes increasingly uncertain with age, particularly prior to 1000 CE (Mann et al. 2008). Limited accuracy in dating also introduces uncertainty into reconstructions of volcanic forcing (Plummer et al. 2012). The largest divergence between the model and the reconstruction occurs during the tenth and eleventh centuries. Other models, irrespective of the magnitude of solar or 
TABLE 2. The RMSE in annual-mean surface air temperature (K) for the mean of each ensemble of climate model simulations, calculated relative to the hemispheric-mean reconstructions of Mann et al. (2008): (a) Northern Hemisphere and (b) Southern Hemisphere. The 95\% confidence intervals are calculated using bootstrapping (Wilks 2011).

\begin{tabular}{lccc}
\hline \hline Ensemble & 501-2000 CE & 501-1850 CE & 1851-2000 CE \\
\hline \multicolumn{4}{c}{ (a) Northern Hemisphere } \\
O & $0.273 \pm 0.008$ & $0.265 \pm 0.008$ & $0.332 \pm 0.036$ \\
OG & $0.273 \pm 0.008$ & $0.282 \pm 0.008$ & $0.168 \pm 0.014$ \\
OGS & $0.266 \pm 0.009$ & $0.274 \pm 0.009$ & $0.183 \pm 0.016$ \\
OGSV & $0.252 \pm 0.010$ & $0.260 \pm 0.011$ & $0.168 \pm 0.018$ \\
(b) Southern Hemisphere \\
O & $0.294 \pm 0.009$ & $0.284 \pm 0.008$ & $0.375 \pm 0.036$ \\
OG & $0.275 \pm 0.008$ & $0.288 \pm 0.009$ & $0.105 \pm 0.013$ \\
OGS & $0.252 \pm 0.008$ & $0.263 \pm 0.008$ & $0.114 \pm 0.012$ \\
OGSV & $0.212 \pm 0.008$ & $0.220 \pm 0.008$ & $0.123 \pm 0.014$ \\
\hline
\end{tabular}

volcanic variations applied, also fail to reproduce this warm period (e.g., Ammann et al. 2007; Jungclaus et al. 2010; Fernández-Donado et al. 2013; Goosse et al. 2012). This is consistent with evidence that the MCA arose through an internal reorganization of the climate system (Mann et al. 2009; Diaz et al. 2011; Graham et al. 2011) and indicates that internal climate variability is an additional source of uncertainty. However, the limitations of the inverse approach in general are highlighted by the fact that we cannot determine whether the reconstruction, the model simulations, or both are the source of the discrepancies.

\section{b. Southern Hemisphere}

The analysis is now extended to the Southern Hemisphere. Figure 3 shows the simulated annual-mean $\mathrm{SH}$ SAT and compares it with the reconstruction of Mann et al. (2008). The model simulates weak internal variability and no observable long-term trend when orbital forcing alone is applied (Fig. 3a), supplemented by a warming trend during the industrial period when changes in greenhouse gases are added (Fig. 3b). Centennial-scale variability becomes more apparent during the preindustrial era when solar forcing is introduced (Fig. 3c) with the ensemble mean remaining above the 1500-1850 CE average for most of the period from 900 to $1300 \mathrm{CE}$. The agreement between the model and the reconstruction is best when volcanic forcing is applied as well (Fig. 3d). Cooling in response to the Kuwae and Tambora eruptions is apparent in both the reconstruction and the model simulations. However, because of the greater fraction of ocean cover in the $\mathrm{SH}$, the magnitude of the temperature changes is smaller than in the NH. A cooling signal in response to the $1258 \mathrm{CE}$ eruption is again missing from the reconstruction.

Table $2 \mathrm{~b}$ shows the RMSE in the mean of each model ensemble, calculated relative to the reconstruction. For the full period (501-2000 CE), the inclusion of each additional forcing reduces the RMSE by a statistically significant amount. Thus, there are detectable influences of greenhouse gases, solar irradiance, and volcanic eruptions on SH temperature. When the RMSE is calculated separately for 501-1850 CE and 1851-2000 CE, we find that only the influences of solar and volcanic forcings are detectable during the preindustrial period, while only the influence of greenhouse gases is detectable during the industrial period. Comparing the results for the two hemispheres, the influences of both solar and volcanic forcing are stronger in the $\mathrm{SH}$. We have therefore been able to show that detectable solar and volcanic signals exist in a reconstruction of $\mathrm{SH}$ temperature spanning the past 1500 years.

We identify the same sources of uncertainty as for the $\mathrm{NH}$ analysis. The agreement between the model and the reconstruction again becomes increasingly poor prior to the fifteenth century (Fig. 3d), and the simulations again fail to capture the peak medieval warmth during the tenth and eleventh centuries. Possible sources of uncertainty therefore include declining skill in the reconstruction or in the forcing datasets used to drive the model, deficiencies in the model physics, and internal climate variability. Once more, this highlights the limitations of the inverse approach, as we cannot determine whether the reconstructions, the model simulations, or both are the source of the discrepancies between them.

\section{c. The role of orbital forcing}

None of the model simulations reproduces the longterm preindustrial (501-1850 CE) cooling trend exhibited by the two hemispheric temperature reconstructions. One possible explanation for this is the response of the multiproxy network to orbitally induced changes in insolation. These changes largely cancel out on the annual and hemispheric scale but vary strongly as a function of both latitude and time of year (Fig. 1a). Any seasonal or geographical biases in the response of a proxy network might therefore cause it to exhibit an exaggerated response to orbital forcing. The potential for such a bias is demonstrated by recent 2000 -yr reconstructions of summer temperature in the Arctic region (Kaufman et al. 2009) and Scandinavia (Esper et al. 2012), both of which reveal strong orbitally driven cooling trends prior to the twentieth century.

The multiproxy network that forms the basis of the reconstructions used here is predominantly based on tree rings (section $2 b$ ). These are typically sampled close to the treeline, where the growing season can be as short as two months (Mann et al. 2012). Furthermore, relatively few of the proxies are located in the tropics, with the bulk being located at mid and high latitudes (Mann 
(a) Orbital

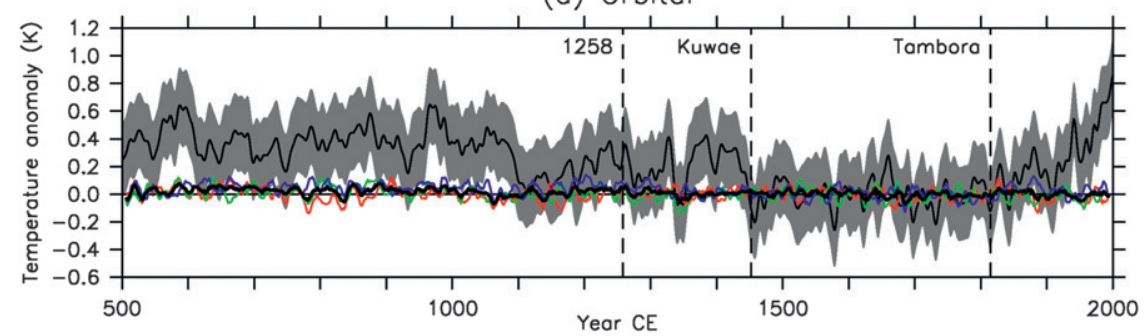

(b) Orbital-Greenhouse

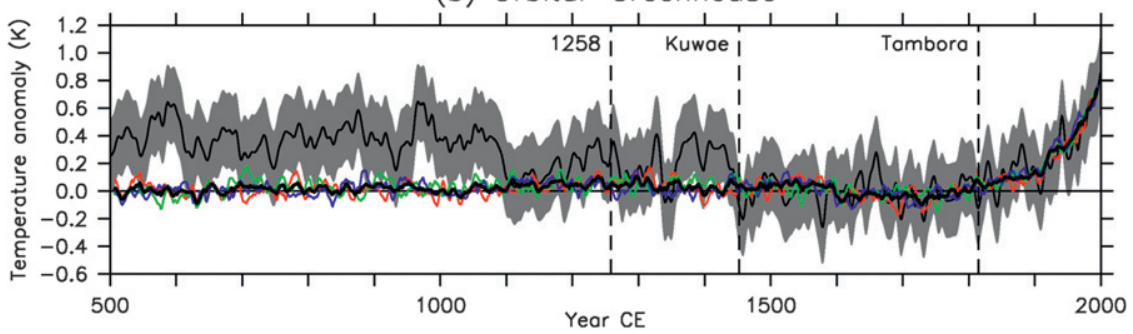

(c) Orbital-Greenhouse-Solar

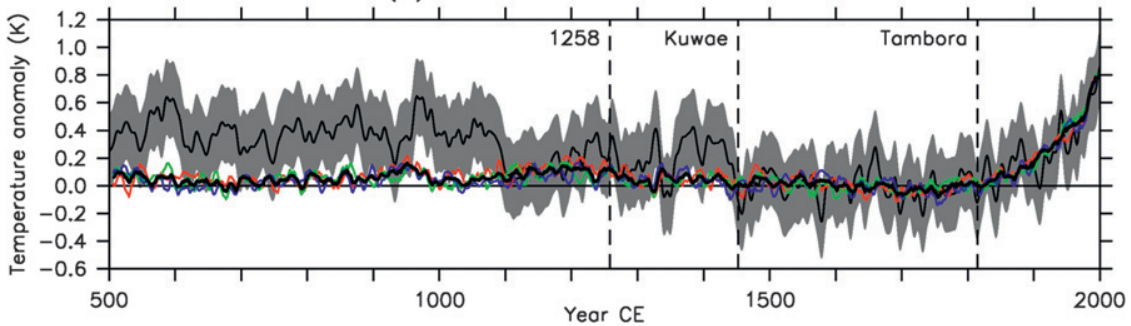

(d) Orbital-Greenhouse-Solar-Volcanic

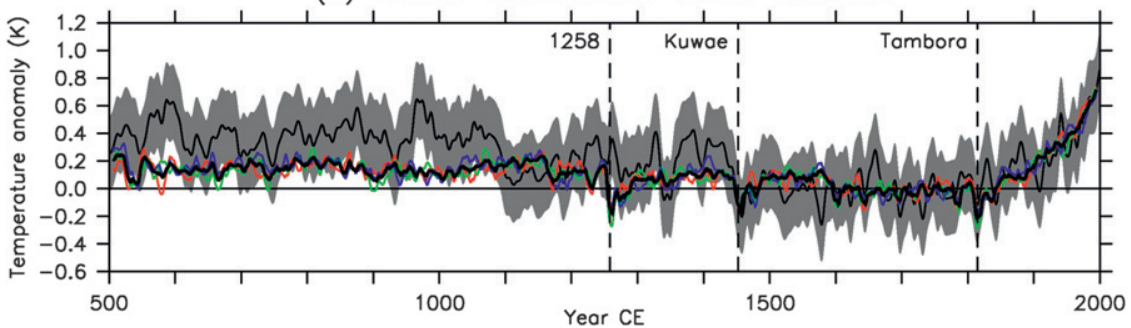

FIG. 3. As in Fig. 2, but for the Southern Hemisphere.

et al. 2008). Thus, while the proxy network is calibrated against annual- and hemispheric-mean temperature, the majority of the individual proxies that comprise the network will respond to changes in temperature during the growing season in the extratropics. This represents a potential source of bias in the response to orbital forcing, which can be investigated using the model simulations.

Figure 4 shows the orbitally forced changes in insolation over the period 501-2000 CE [calculated using the method of Berger (1978)], the mean temperature simulated by model ensemble OGSV, and the hemispheric temperature reconstructions of Mann et al. (2008). Four different temporal and spatial domains are used to calculate the hemispheric averages of insolation and simulated temperature. In the DEFAULT case, the annual and hemispheric means are calculated, as in the preceding analysis. In the GROW case, the averages are calculated for the growing season only. In the $\mathrm{NH}$, this is taken as July-August following Mann et al. (2012); in the $\mathrm{SH}$, where tree rings can be sampled at lower elevations and latitudes, this is taken as October-November following Fowler et al. (2012). Regardless, the conclusions of the following analysis are insensitive to the exact definition of the growing season. In the EXTRA case, the averages are calculated for the extratropics only, which are taken as the regions $30^{\circ}-90^{\circ} \mathrm{N}$ and $90^{\circ}-30^{\circ} \mathrm{S}$, respectively. Finally, in the GROW+EXTRA case, the 
(a) Northern Hemisphere insolation

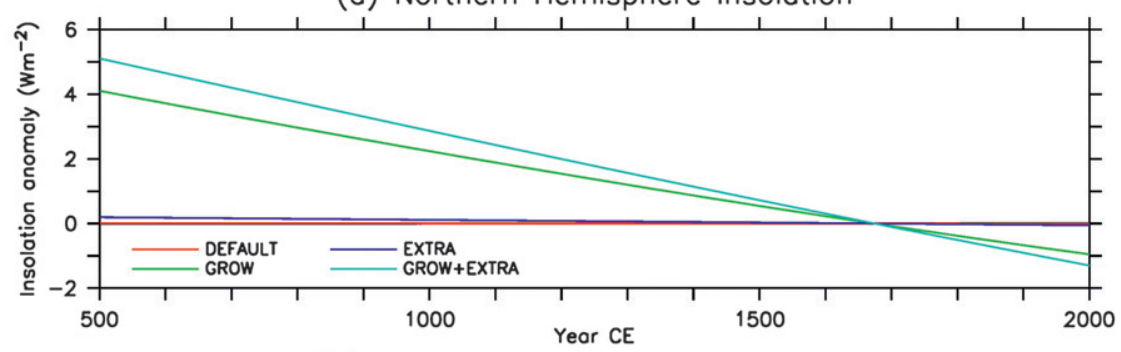

(b) Northern Hemisphere temperature

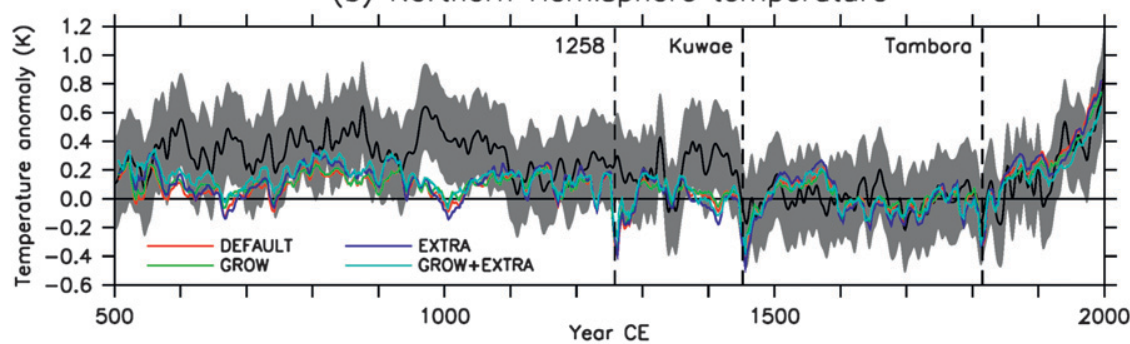

(c) Southern Hemisphere insolation

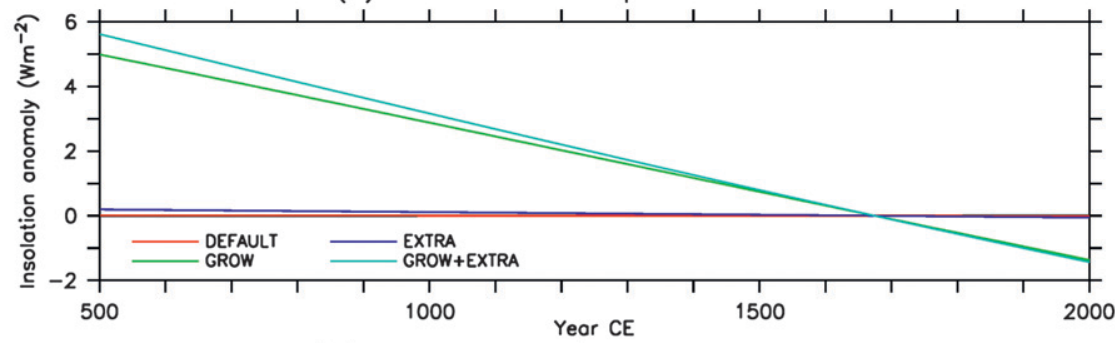

(d) Southern Hemisphere temperature

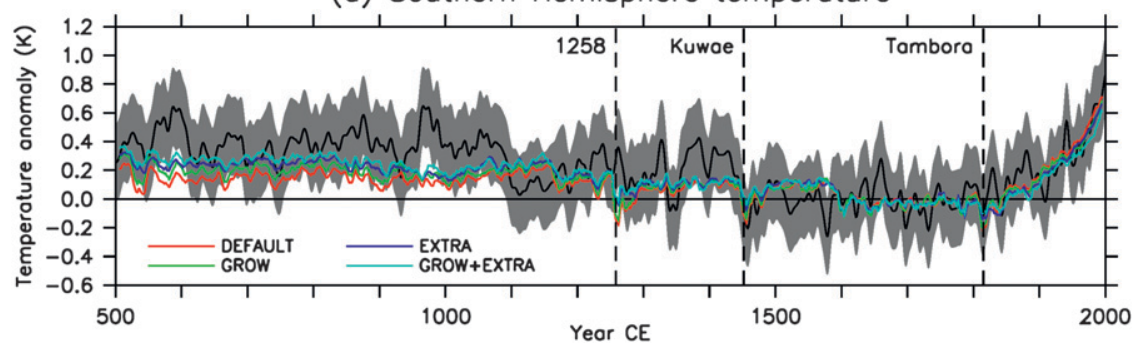

FIG. 4. The changes in insolation and temperature in the Northern and Southern Hemispheres for a variety of temporal and spatial domains: (a),(c) top-of-atmosphere insolation and (b),(d) surface air temperature according to the reconstructions of Mann et al. (2008) and the mean of model ensemble OGSV. In each case, DEFAULT (red) is the annual and hemispheric mean, GROW (green) is the mean for the growing season only, EXTRA (dark blue) is the mean for the extratropics only, and GROW+EXTRA (light blue) is the mean for the growing season and extratropics only. The changes in insolation shown are those due to orbital forcing only. The $95 \%$ confidence interval for Mann et al. (2008) is indicated by gray shading. The values shown for the model simulations are 10-yr running means. All values are expressed as anomalies relative to the 1500-1850 CE mean. Vertical dashed lines indicate the volcanic eruptions of $1258 \mathrm{CE}$ (unknown location), $1452 \mathrm{CE}$ (Kuwae), and $1815 \mathrm{CE}$ (Tambora).

averages are calculated for the growing season and extratropics only. Figures $4 \mathrm{a}$ and $4 \mathrm{c}$ show that orbital forcing becomes much more important when considering changes on a seasonal scale. Growing season insolation in both hemispheres declines by more than $5 \mathrm{~W} \mathrm{~m}^{-2}$ between
501 and $2000 \mathrm{CE}$, and by more than $6 \mathrm{~W} \mathrm{~m}^{-2}$ in the extratropics. The model simulates stronger preindustrial cooling trends when these potential biases are taken into account and is therefore more consistent with the reconstructions (Figs. 4b,d). 
TABLE 3. The RMSE in annual-mean surface air temperature (K) for the mean of each ensemble of climate model simulations over the period 501-1850 CE, calculated relative to the hemispheric-mean reconstructions of Mann et al. (2008): (a) Northern Hemisphere and (b) Southern Hemisphere. Values are shown for four cases: DEFAULT (the annual and hemispheric mean), GROW (the mean for the growing season only), EXTRA (the mean for the extratropics only), and GROW+EXTRA (the mean for the growing season and extratropics only). The $95 \%$ confidence intervals are calculated using bootstrapping (Wilks 2011).

\begin{tabular}{lcccr}
\hline \hline Ensemble & DEFAULT & GROW & EXTRA & GROW+EXTRA \\
\hline \multicolumn{4}{c}{ (a) Northern Hemisphere } \\
O & $0.265 \pm 0.008$ & $0.251 \pm 0.008$ & $0.243 \pm 0.008$ & $0.212 \pm 0.007$ \\
OG & $0.282 \pm 0.008$ & $0.266 \pm 0.008$ & $0.261 \pm 0.008$ & $0.228 \pm 0.007$ \\
OGS & $0.274 \pm 0.009$ & $0.255 \pm 0.008$ & $0.262 \pm 0.010$ & $0.225 \pm 0.008$ \\
OGSV & $0.260 \pm 0.011$ & $0.248 \pm 0.012$ & $0.260 \pm 0.012$ & $0.239 \pm 0.015$ \\
O & $0.284 \pm 0.008$ & (b) Southern Hemisphere & & $0.234 \pm 0.007$ \\
OG & $0.288 \pm 0.009$ & $0.247 \pm 0.007$ & $0.258 \pm 0.008$ & $0.237 \pm 0.008$ \\
OGS & $0.263 \pm 0.008$ & $0.254 \pm 0.008$ & $0.258 \pm 0.008$ & $0.207 \pm 0.007$ \\
OGSV & $0.220 \pm 0.008$ & $0.198 \pm 0.007$ & $0.224 \pm 0.007$ & $0.173 \pm 0.007$ \\
\hline
\end{tabular}

Biases of this nature might distort attempts to attribute past climatic changes to specific external forcings. To explore this possibility, Table 3 shows the same RMSEs that were calculated in the preceding analysis. This time, only the preindustrial period (501-1850 CE) is considered. For the NH (Table 3a), both the GROW and EXTRA biases reduce the RMSE for ensemble O, reflecting increasing skill as the model simulates a stronger preindustrial cooling trend. Both of these biases also reduce the difference in RMSE between ensembles OGS and OGSV sufficiently that we no longer find any detectable influence of volcanic eruptions on NH temperature. In the EXTRA and GROW+EXTRA cases, ensemble $\mathrm{O}$ has the smallest RMSE of all the ensembles, indicating that the application of orbital forcing alone optimizes the agreement between the model and the reconstruction. The results for the SH differ considerably (Table 3b). The stronger preindustrial cooling trend simulated by ensemble $\mathrm{O}$ again leads to better agreement with the reconstruction in all cases. However, there continues to be a detectable influence of both solar irradiance and volcanic eruptions on SH temperature. Ensemble OGSV consistently has the smallest RMSE of all the ensembles, even in the GROW+EXTRA case.

Overall, we find that the model can reproduce at least some of the reconstructed long-term preindustrial cooling trend in each hemisphere but only once potential seasonal or geographical biases are taken into account. If the model is accurate, this suggests that the cooling trend in the reconstructions is, at least in part, an artifact that arises because of these biases. This counters the argument of Esper et al. (2012) by suggesting that, on the annual and hemispheric scale, current multiproxy reconstructions overestimate rather than underestimate the magnitude of the preindustrial cooling trend. Further analysis using multiple models would be required to confirm this conclusion.

The complementary roles of orbital and volcanic forcing undermine our previous conclusion that there is a detectable influence of volcanic eruptions on $\mathrm{NH}$ temperature. Volcanic forcing improves the agreement between the model and the reconstruction, but it does so by increasing the magnitude of the simulated preindustrial cooling trend. This brings the model into better agreement with the potentially exaggerated trend in the reconstruction. Once potential seasonal or geographical biases in the reconstruction are taken into account, orbital forcing alone provides the best explanation of this trend. While this indicates that the inverse approach can restrict our ability to identify the drivers of past climate, our conclusion that there are detectable influences of solar irradiance and volcanic eruptions on $\mathrm{SH}$ temperature remains robust.

\section{The climate of the central Pacific}

In the previous section, we studied the role of external forcings in driving hemispheric-scale temperature and found detectable roles of solar irradiance and volcanic eruptions in driving the $\mathrm{SH}$ climate. A detectable role of greenhouse gases was also found in driving the climates of both hemispheres during the industrial period. We now extend this work to study the role of natural and anthropogenic forcings in driving the climate of the central Pacific. We construct a pseudocoral indicator and then use this to compare the model simulations with the coral $\delta^{18} \mathrm{O}$ record (section 2c). By examining changes in both the mean state of the central Pacific and ENSO, we will be able to use the model simulations to test the conclusion of Cobb et al. (2003) that changes in 
ENSO variability are decoupled from the mean state and instead arise from within the internal dynamics of the ENSO system itself. As this analysis employs a simple forward model, it represents an application of the forward approach to paleoclimate data-model comparison (section 1b).

\section{a. Pseudocoral derivation}

Coral $\delta^{18} \mathrm{O}$ is influenced by both the temperature and $\delta^{18} \mathrm{O}$ value of the ambient seawater (Epstein et al. 1953; Weber and Woodhead 1972; Juillet-Leclerc and Schmidt 2001). To estimate the value of coral $\delta^{18} \mathrm{O}$ within their isotope-enabled climate model, Brown et al. (2006) therefore use the following relationship:

$$
\delta^{18} \mathrm{O}_{\text {coral }}=\delta^{18} \mathrm{O}_{\text {ocean }}+a(\mathrm{SST})+b .
$$

Most climate models, including the one employed in this study, cannot use this approach as they do not include any representation of ${ }^{18} \mathrm{O}$. The pseudocoral approach therefore approximates the $\delta^{18} \mathrm{O}$ signal that would be generated by a climate model if isotopes were included. This has been accomplished previously by relating coral $\delta^{18} \mathrm{O}$ to local sea surface temperature and salinity (Thompson et al. 2011) or by relating the ENSO signal in coral $\delta^{18} \mathrm{O}$ to local sea surface temperature and precipitation (Brown et al. 2008). Here, we follow the approach of Brown et al. (2008) and construct a pseudocoral indicator that contains the ENSO signal as recorded in local climatic variables at the site of a coral.

Based on previous studies (Brown et al. 2006, 2008; Thompson et al. 2011) and physical understanding of the factors influencing coral $\delta^{18} \mathrm{O}$, we consider four model variables as being potential predictors of the simulated ENSO signal: sea surface temperature SST, sea surface salinity SSS, precipitation $P$, and evaporation $E$. The first of these variables appears directly in Eq. (1) and describes the thermal influence on $\operatorname{coral} \delta^{18} \mathrm{O}$. The other three variables can all be expected to contain information about $\delta^{18} \mathrm{O}_{\text {ocean }}$, and therefore to contain information about the isotopic influence on coral $\delta^{18} \mathrm{O}$ : SSS is strongly correlated with $\delta^{18} \mathrm{O}_{\text {ocean }}$ because both quantities are directly influenced by the surface freshwater balance (Cole and Fairbanks 1990; Fairbanks et al. 1997; Rohling and Bigg 1998), while $P$ and $E$ both influence $\delta^{18} \mathrm{O}_{\text {ocean }}$ directly.

A 1000-yr CSIRO Mk3L preindustrial control simulation is used to construct a pseudocoral from these model variables. Stepwise regression is used to screen the set of potential predictors, with cross validation used to protect against statistical overfitting (Wilks 2011). Table 4 shows the outcome of this process, with each of the model variables being progressively regressed onto
TABLE 4. Stepwise regression of the simulated monthly SST anomaly in the Niño- 3.4 region $\left(5^{\circ} \mathrm{S}-5^{\circ} \mathrm{N}, 170^{\circ}-120^{\circ} \mathrm{W}\right)$ onto the simulated monthly anomalies in SST, SSS, $P$, and $E$ at Palmyra Island $\left(6^{\circ} \mathrm{N}, 162^{\circ} \mathrm{W}\right)$. At each step, all the available potential predictors are examined and the one that produces the best fit when incorporated into the regression equation is selected (indicated by boldface text in the table). Cross validation is used to protect against overfitting, with 45-month blocks of data reserved for independent validation (Wilks 2011). The calibration error represents the mean-square error for each of the 11956 fits performed, while the validation error represents the mean-square error in the predicted value for the middle month of each 45-month validation period. The data for this exercise are taken from a 1000-yr preindustrial control simulation.

\begin{tabular}{lcc}
\hline \hline & \multicolumn{2}{c}{ Mean-square error $\left(\mathrm{K}^{2}\right)$} \\
\cline { 2 - 3 } Predictor(s) & Calibration & Validation \\
\hline & Step 1: One predictor \\
SST & $\mathbf{0 . 1 2 9}$ & $\mathbf{0 . 1 2 9}$ \\
SSS & 0.224 & 0.225 \\
$P$ & 0.267 & 0.269 \\
$E$ & 0.304 & 0.306 \\
& Step 2: Two predictors & \\
SST, SSS & $\mathbf{0 . 1 1 4}$ & $\mathbf{0 . 1 1 5}$ \\
SST, $P$ & 0.124 & 0.125 \\
SST, $E$ & 0.119 & 0.120 \\
SST, SSS, $P$ & Step 3: Three predictors & \\
SST, SSS, $\boldsymbol{E}$ & 0.114 & 0.115 \\
SST, SSS, $\boldsymbol{E}, \boldsymbol{P}$ & $\mathbf{0 . 1 0 3}$ & $\mathbf{0 . 1 0 4}$ \\
& Step 4: Four predictors & \\
& $\mathbf{0 . 0 9 9}$ & $\mathbf{0 . 1 0 0}$ \\
\hline
\end{tabular}

the simulated Niño-3.4 SST anomaly. At the first step, each of the four potential predictors is considered with the one that produces the best univariate regression being selected. At subsequent steps, each of the remaining potential predictors are considered for incorporation into the regression equation with the one that produces the best fit overall being selected.

For the purposes of cross validation, 45-month blocks of data are reserved. The autocorrelation coefficient for the simulated Niño-3.4 SST anomaly falls to zero at a lag of 22 months, and the use of a 45 -month validation block therefore ensures that the value being predicted is statistically independent of the values used to derive the fit. At each step, the fit is performed $11956(=12000-$ $45+1)$ times, and the mean-square error is calculated for the fit (calibration error) and for the predicted value for the middle month of the validation period (validation error). If the incorporation of an additional predictor reduces both the calibration error and the validation error, it can be concluded that it improves the predictive ability of the pseudocoral.

In this case, all four model variables are selected. SST is selected first, followed by SSS, $E$, and then $P$. Based on the final step of the regression process, we therefore 
define the following pseudocoral indicator as being applicable to the modeling framework used here:

$$
C=\underset{( \pm 0.015)}{0.692} \Delta \mathrm{SST}-\underset{( \pm 0.056)}{0.708} \Delta \mathrm{SSS}+\underset{( \pm 0.002)}{0.023} \Delta P+\underset{( \pm 0.013)}{0.248} \Delta E,
$$

where $\Delta \mathrm{SST}, \Delta \mathrm{SSS}, \Delta P$, and $\Delta E$ are the monthly anomalies in SST (K), SSS (psu), $P\left(\mathrm{~mm} \mathrm{day}^{-1}\right)$, and $E\left(\mathrm{~mm} \mathrm{day}^{-1}\right)$, respectively. The $95 \%$ confidence intervals are shown for each of the regression coefficients and are determined using bootstrapping. The term $C$ is a temperature anomaly with units of kelvins and describes the magnitude of the simulated ENSO signal that might be expected to be recorded by coral $\delta^{18} \mathrm{O}$ at Palmyra Island.

The pseudocoral derived here differs from the bivariate pseudocorals used by Brown et al. (2008) and Thompson et al. (2011). Although the incorporation of the $\Delta P$ and $\Delta E$ terms into our pseudocoral only increases the fraction of ENSO variance described from $65 \%$ to $70 \%$, this nonetheless demonstrates the potential to improve pseudocoral formulations by incorporating more complete descriptions of the physical processes that determine the evolution of coral $\delta^{18} \mathrm{O}$ (Stevenson et al. 2013). In turn, this demonstrates the potential value of the pseudocoral approach as an intermediate step toward full forward modeling, as well as the need for more complete understanding of the controls on seawater $\delta^{18} \mathrm{O}$ near proxy sites.

\section{b. Changes in the mean state}

The pseudocoral can be used to compare the model simulations with the true coral $\delta^{18} \mathrm{O}$ record. Figure 5 shows the record of Cobb et al. (2003) and compares it with pseudocorals derived from the preindustrial control simulation and the three members of ensemble OGSV. Coral $\delta^{18} \mathrm{O}$ is normalized using the mean and standard deviation for the period 1886-1975 CE, which is the baseline used by Cobb et al. (2003). To allow direct comparison with the pseudocorals, the sign has been inverted such that positive values correspond to warmer and wetter conditions. The pseudocorals are also normalized using the mean and standard deviation for the period 1886-1975 CE (except for the preindustrial control, which is normalized using the mean and standard deviation for the control simulation).

The coral $\delta^{18} \mathrm{O}$ (Fig. 5a) exhibits interdecadal variability with a similar amplitude and frequency to that exhibited by the preindustrial control simulation (Fig. 5b), suggesting an internal origin. However, the 10-yr running mean deviates from the 1886-1975 CE mean by more than two standard deviations on two occasions: a negative excursion during the tenth century and a positive excursion at the end of the twentieth century. No deviations of this magnitude are apparent from the control simulation, suggesting that these events may not have arisen solely as a result of natural climate variability.

From Figs. 5c-e, it is apparent that the choice of an 1886-1975 CE baseline causes the pseudocoral time series to be generally negative during the preindustrial period, with a mean value of around -0.6 standard deviations prior to $1850 \mathrm{CE}$. However, there are only three occasions where the 10-yr running mean of the pseudocoral decreases to more than two standard deviations below the 1886-1975 CE mean. Two of these events coincide with the $1258 \mathrm{CE}$ and Kuwae eruptions, indicating a volcanic origin. However, the third ensemble member also experiences a cooling event centered on $981 \mathrm{CE}$, which does not correspond to any external forcing and therefore appears to be internal in origin.

The above results suggest that the excursion in coral $\delta^{18} \mathrm{O}$ during the mid-tenth century, which indicates a period of relatively cool and dry conditions (Cobb et al. 2003), is due partly to the choice of climatological base period and partly to either a volcanic eruption or internal variability. A volcanic explanation is possible, as the maximum excursion in coral $\delta^{18} \mathrm{O}$ is centered on $940 \mathrm{CE}$ and follows a modest eruption in $939 \mathrm{CE}$ (Gao et al. 2008). However, if the excursion represents a response to external forcing, then it should also be captured by the pseudocorals. This is not the case, suggesting either that the mid-tenth-century climatic anomaly was internal in origin, or alternatively that there are deficiencies in the pseudocoral approach or in the forcing time series used to drive the model.

In contrast to the earlier excursions, the anomaly in coral $\delta^{18} \mathrm{O}$ at the end of the twentieth century coincides with increases in the pseudocoral over the same period within the forced model simulations. The magnitude of the increase in coral $\delta^{18} \mathrm{O}$ is larger than the magnitude of the increase in the pseudocorals. However, the fact that the pseudocorals derived from the three forced simulations (Figs. 5c-e) all exceed the range of natural variability within the control simulation (Fig. 5b) suggests that the excursion is a response to anthropogenic climate change. Coral-based reconstructions of late-twentiethcentury SST and SSS trends from Palmyra Island and neighboring sites support this conclusion and suggest a general freshening of the tropical Pacific Ocean (Nurhati et al. 2009, 2011). Nonetheless, the excursions remain fairly short in duration and so attribution of these changes to anthropogenic influences must be made with caution (Stevenson 2012; Stevenson et al. 2012).

Having established that the pseudocorals are capable of reproducing the broad features of the coral $\delta^{18} \mathrm{O}$ 
(a) Coral

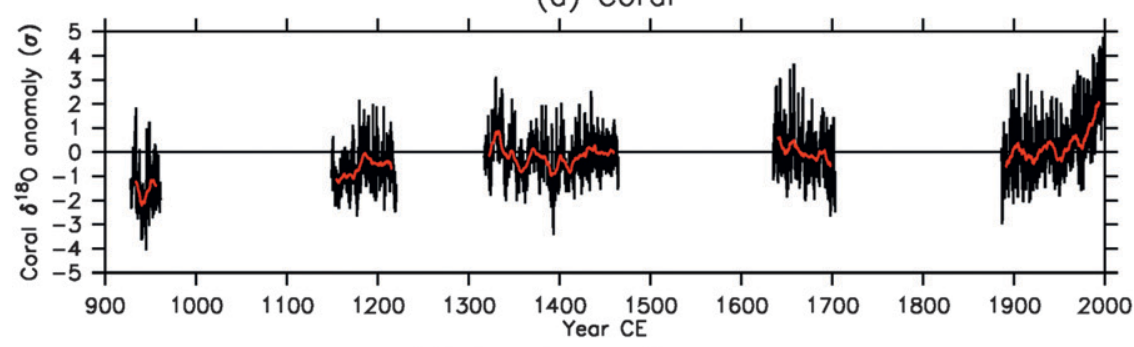

(b) Pre-industrial control

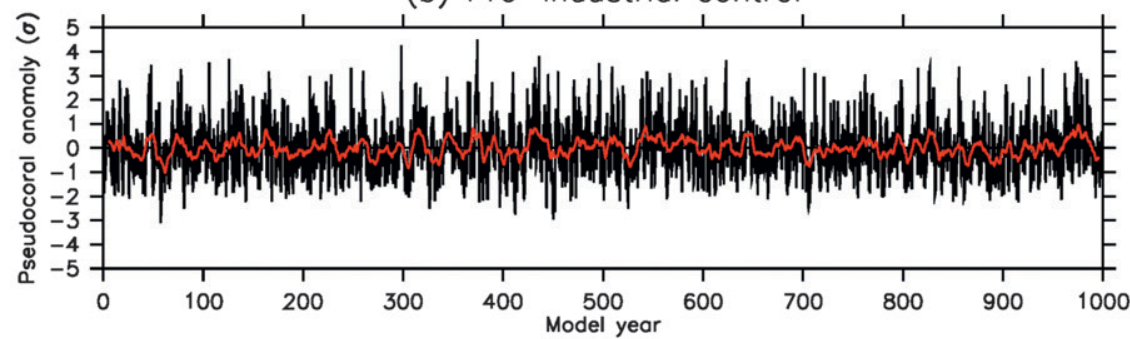

(c) Member 1

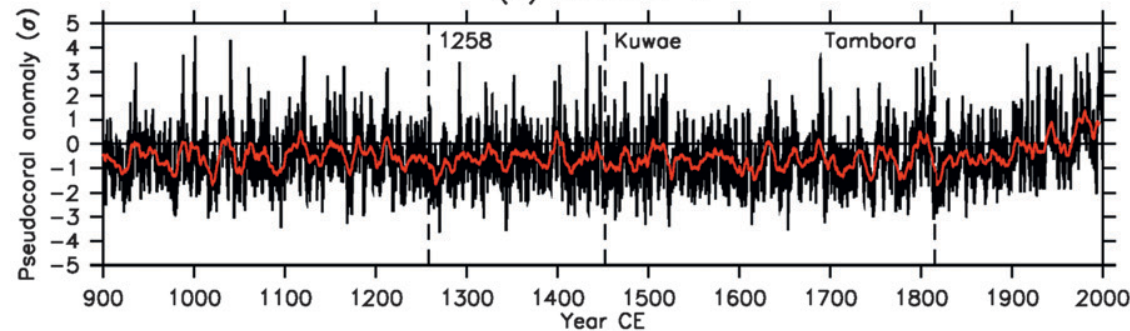

(d) Member 2

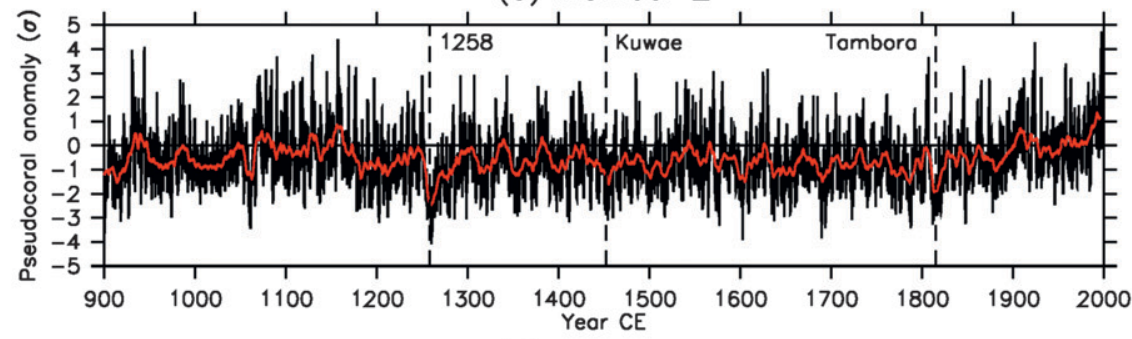

(e) Member 3

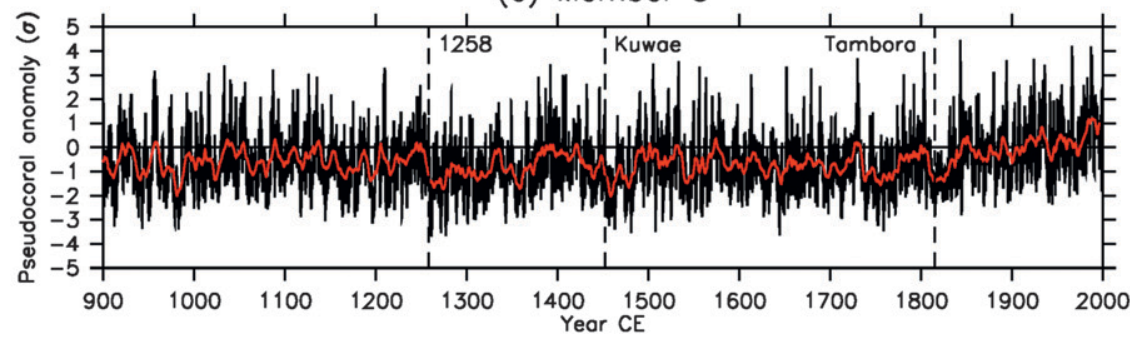

FIG. 5. The normalized monthly anomalies (standard deviations) in (a) coral $\delta^{18} \mathrm{O}$ at Palmyra Island $\left(6^{\circ} \mathrm{N}, 162^{\circ} \mathrm{W}\right)$, (b) pseudocoral derived from a preindustrial control simulation, and pseudocorals derived from members (c) 1, (d) 2, and (e) 3 of ensemble OGSV. The preindustrial control pseudocoral is normalized using the mean and standard deviation for the control simulation. All other values are normalized using the mean and standard deviation for the period 1886-1975 CE. The sign of the normalized coral $\delta^{18} \mathrm{O}$ has been inverted such that positive values correspond to warmer and wetter conditions, to aid comparison with the pseudocorals. Monthly anomalies are shown in black and the 10-yr running mean is shown in red. Vertical dashed lines indicate the volcanic eruptions of $1258 \mathrm{CE}$ (unknown location), 1452 CE (Kuwae), and 1815 CE (Tambora). 
record, we use them to make a more systematic assessment of the role of external forcings in driving the climate of the central Pacific. Table 5 shows the correlations between the pseudocorals derived from the forced model simulations and the individual forcing time series used to drive the model. The analysis is restricted to 901-2000 CE, reflecting the period spanned by the coral $\delta^{18} \mathrm{O}$ record. On annual time scales (Table 5a), statistically significant roles of both greenhouse gases and solar irradiance are identified. On decadal time scales (Table 5b), a systematic role of volcanoes in driving the local climate also becomes apparent.

The model simulations allow us to explore the mechanisms whereby external forcings drive changes in the state of the tropical Pacific. Two mechanisms will be investigated here: the ocean dynamical thermostat (hereafter ODT) mechanism, whereby warming in the tropics causes enhanced upwelling in the eastern Pacific and therefore increases the magnitude of the zonal SST gradient (Clement et al. 1996); and the "Weaker Walker" (hereafter WW) mechanism, whereby global-scale warming causes a weakening of the Walker circulation that is manifested in a reduction in the zonal sea level pressure (SLP) gradient across the equatorial Pacific (Held and Soden 2006; Vecchi et al. 2006).

Figure 6 shows scatterplots of $\Delta$ SST (the difference in SST between the Niño-4 and Niño-3 regions) and $\Delta$ SLP [the difference in SLP between the central-east Pacific $\left(5^{\circ} \mathrm{S}-5^{\circ} \mathrm{N}, 160^{\circ}-80^{\circ} \mathrm{W}\right)$ and the Indian Ocean-west Pacific $\left.\left(5^{\circ} \mathrm{S}-5^{\circ} \mathrm{N}, 80^{\circ}-160^{\circ} \mathrm{E}\right)\right]$ versus radiative forcing for each of the three external forcings considered in this section. Values of the Spearman rank correlation coefficient are provided. Greenhouse gas forcing is weak prior to $1850 \mathrm{CE}$, and volcanic forcing is zero in many decades; many of the values shown are therefore clustered around zero radiative forcing. Considerable scatter is apparent in all cases, due to both internal variability and the effects of other forcings.

The ODT mechanism predicts a positive correlation between $\Delta$ SST and radiative forcing. In Figs. 6a-c, a weak positive relationship is apparent for each of the three forcings, but the null hypothesis of no correlation cannot be rejected at the $5 \%$ significance level in any case. The WW mechanism predicts a negative correlation between $\triangle$ SLP and radiative forcing. Negative relationships are indeed apparent in Figs. 6d and 6e, and this relationship is statistically significant in the case of greenhouse gases. This analysis therefore suggests that the response of the model on decadal time scales is characterized by a WW response to changing anthropogenic greenhouse gases. However, only a much more detailed analysis could confirm the operation of this dynamical mechanism.

These results are consistent with observational evidence for the operation of the WW mechanism during
TABLE 5. The correlation between the pseudocorals derived from the members of ensemble OGSV and the individual forcings used to drive the model for the period 901-2000 CE: (a) the correlation between the annual-mean pseudocorals and the annualmean forcings, (b) the correlation between the decadal-mean pseudocorals and the decadal-mean forcings, and (c) the correlation between the running 30-yr standard deviation for the pseudocorals, after applying a 2-7-yr bandpass filter, and the running 30 -yr mean for the forcings. In (a) and (b), the ensemble mean is the arithmetic mean of each ensemble member; in (c), the ensemble mean is the root-mean-square of the standard deviation for each ensemble member. Greenhouse gas concentrations are converted to a radiative forcing before calculating the correlations. For values shown in boldface, the null hypothesis of no correlation can be rejected at the $5 \%$ significance level [as determined using the random-phase test of Ebisuzaki (1997)].

\begin{tabular}{lccr}
\hline $\begin{array}{c}\text { Ensemble } \\
\text { member }\end{array}$ & $\begin{array}{c}\text { Greenhouse } \\
\text { gases }\end{array}$ & $\begin{array}{c}\text { Solar } \\
\text { irradiance }\end{array}$ & $\begin{array}{r}\text { Volcanic } \\
\text { eruptions }\end{array}$ \\
\hline \multicolumn{4}{c}{ (a) Annual mean } \\
1 & $+\mathbf{0 . 3 1}$ & +0.11 & \\
2 & $+\mathbf{0 . 2 8}$ & $+\mathbf{0 . 1 7}$ & +0.00 \\
3 & $+\mathbf{0 . 3 1}$ & $+\mathbf{0 . 1 9}$ & +0.05 \\
Mean & $+\mathbf{0 . 4 7}$ & $+\mathbf{0 . 2 5}$ & +0.04 \\
& $($ b) Decadal mean & \\
1 & $+\mathbf{0 . 5 9}$ & +0.22 & +0.12 \\
2 & $+\mathbf{0 . 5 0}$ & $+\mathbf{0 . 2 9}$ & $+\mathbf{0 . 3 3}$ \\
3 & $+\mathbf{0 . 5 9}$ & $+\mathbf{0 . 3 5}$ & $+\mathbf{0 . 2 3}$ \\
Mean & $+\mathbf{0 . 7 1}$ & $+\mathbf{0 . 3 7}$ & $+\mathbf{0 . 2 9}$ \\
& $(\mathbf{c})$ & $30-$ yr standard deviation & \\
1 & +0.02 & -0.24 & 0.00 \\
2 & +0.14 & +0.27 & +0.10 \\
3 & $+\mathbf{0 . 3 2}$ & -0.09 & +0.03 \\
Mean & +0.30 & -0.04 & +0.09 \\
\hline
\end{tabular}

the industrial period, as well as with the response of other climate system models to both past and projected future changes in greenhouse gases (Vecchi et al. 2006; DiNezio et al. 2011). The lack of an apparent ODT mechanism is inconsistent with the response of the highly simplified Zebiak-Cane model to medium to strong solar forcing (Mann et al. 2005; Emile-Geay et al. 2007) and large volcanic eruptions (Mann et al. 2005; Emile-Geay et al. 2008). However, in another climate system model, the ODT mechanism is found to be opposed by other terms in its response to volcanic eruptions (McGregor and Timmermann 2011).

\section{c. Changes in ENSO variability}

The coral $\delta^{18} \mathrm{O}$ and pseudocoral records are now used as proxies for ENSO, with the magnitudes of their interannual variations used to estimate the amplitude of ENSO variability. Figure 7 shows the running $30-y r$ standard deviation, derived from both the coral $\delta^{18} \mathrm{O}$ record and the pseudocorals. A 2-7-yr bandpass filter is applied to the data beforehand in order to select variability in the ENSO band. To allow a direct comparison between the 
(a) Greenhouse gases

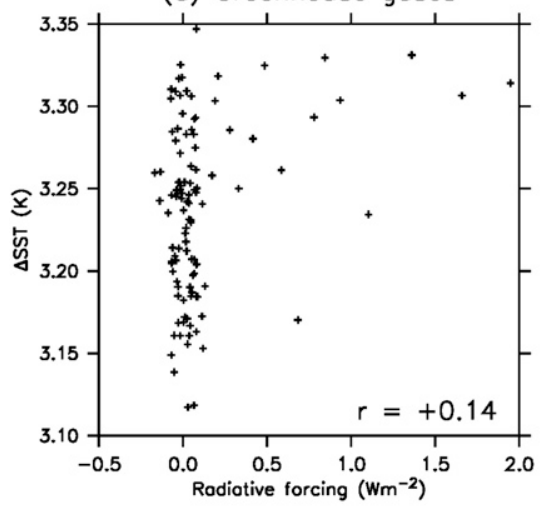

(d) Greenhouse gases

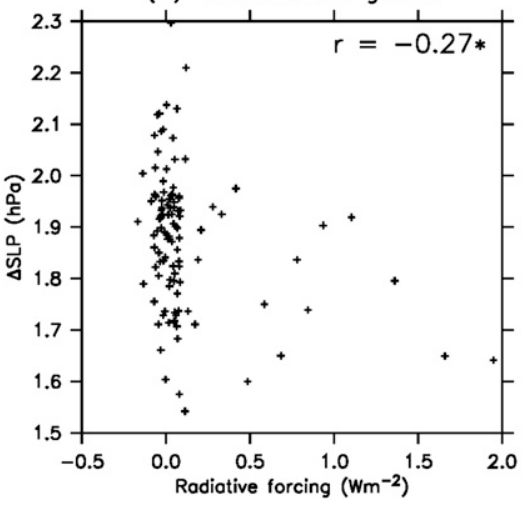

(b) Solar irradiance

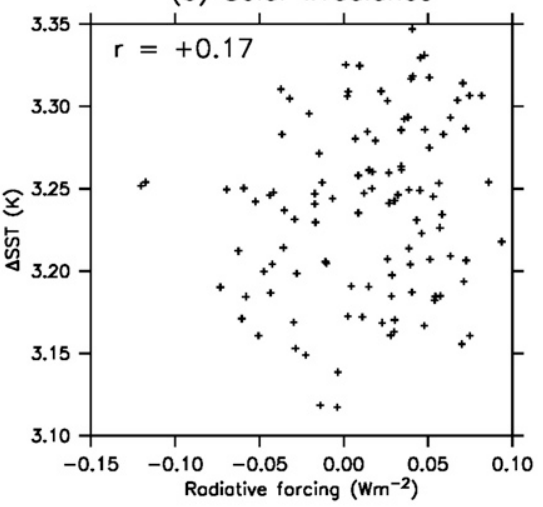

(e) Solar irradiance

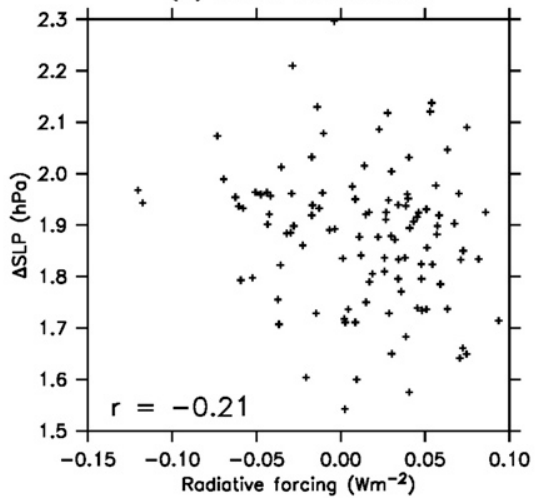

(c) Volcanic eruptions

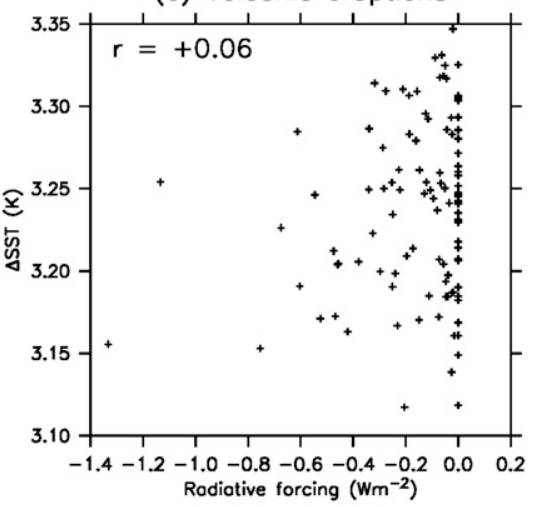

(f) Volcanic eruptions

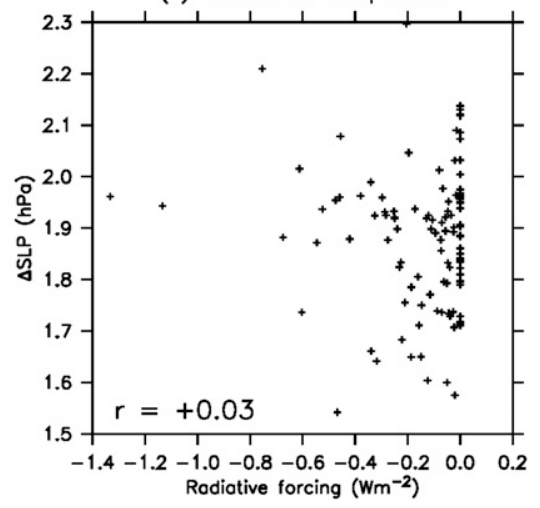

FIG. 6. Scatterplots of decadal-mean $\Delta \mathrm{SST}(\mathrm{K})$ and $\Delta \mathrm{SLP}(\mathrm{hPa})$ vs decadal-mean radiative forcing $\left(\mathrm{W} \mathrm{m}^{-2}\right)$ for the mean of ensemble OGSV over the period 901-2000 CE: greenhouse gases vs (a) $\Delta$ SST and (d) $\Delta$ SLP, solar irradiance vs (b) $\Delta$ SST and (e) $\Delta$ SLP, and volcanic eruptions vs (c) $\Delta \mathrm{SST}$ and (f) $\Delta \mathrm{SLP}$. The term $\Delta \mathrm{SST}$ is the difference in sea surface temperature between the Niño- $4\left(5^{\circ} \mathrm{S}-5^{\circ} \mathrm{N}, 160^{\circ} \mathrm{E}-\right.$ $\left.150^{\circ} \mathrm{W}\right)$ and Niño-3 $\left(5^{\circ} \mathrm{S}-5^{\circ} \mathrm{N}, 150^{\circ}-90^{\circ} \mathrm{W}\right)$ regions. The term $\Delta \mathrm{SLP}$ is the difference in sea level pressure between the central-east Pacific $\left(5^{\circ} \mathrm{S}-5^{\circ} \mathrm{N}, 160^{\circ}-80^{\circ} \mathrm{W}\right)$ and Indian Ocean-west Pacific $\left(5^{\circ} \mathrm{S}-5^{\circ} \mathrm{N}, 80^{\circ}-160^{\circ} \mathrm{E}\right)$. Values of the Spearman rank correlation coefficient are shown. An asterisk after the value indicates that the null hypothesis of no correlation can be rejected at the 5\% significance level [as determined using the random-phase test of Ebisuzaki (1997)].

proxy data and the model, the amplitudes of $\delta^{18} \mathrm{O}$ and the pseudocorals are expressed relative to a measure of the long-term average variability. For the preindustrial control pseudocoral, the running standard deviations are divided by the mean value for the control simulation. All other values are divided by the mean standard deviation for the period 1886-1975 CE.

The coral $\delta^{18} \mathrm{O}$ record (Fig. 7a) indicates generally reduced ENSO variability relative to present prior to $1500 \mathrm{CE}$; during the fourteenth century, the standard deviation falls to as little as 0.40 of the 1886-1975 CE value. However, the ENSO variability is similar to present after $1600 \mathrm{CE}$. The ratio between the maximum and minimum value of the 30 -yr standard deviation is 3.4 , which is greater than the equivalent ratio of 2.4 for the preindustrial control pseudocoral (Fig. 7b). The variations in the amplitude of ENSO over the past 1100 years are therefore greater than the magnitude of the simulated preindustrial internal variability. This suggests either that the model underestimates the magnitude of low-frequency modulation of ENSO or that external forcings are driving changes in ENSO variability.

The pseudocorals derived from the forced model simulations are shown in Fig. 7c. The ratio between the maximum and minimum amplitudes of ENSO variability spanned by the three pseudocorals is 3.2 , which is greater than for the control pseudocoral and in better agreement with the coral $\delta^{18} \mathrm{O}$ record. However, the pseudocorals exhibit no coherent response to external forcings. Table $5 \mathrm{c}$ shows the correlations between the 30-yr standard deviation derived from each pseudocoral and the individual forcing time series used to drive the model. One of the three ensemble members exhibits a statistically significant relationship with greenhouse gas forcing at the $95 \%$ confidence level, but this relationship is not significant within the ensemble as a whole. Within the modeling framework employed here we therefore find no robust evidence that external forcings influence 
(a) Coral

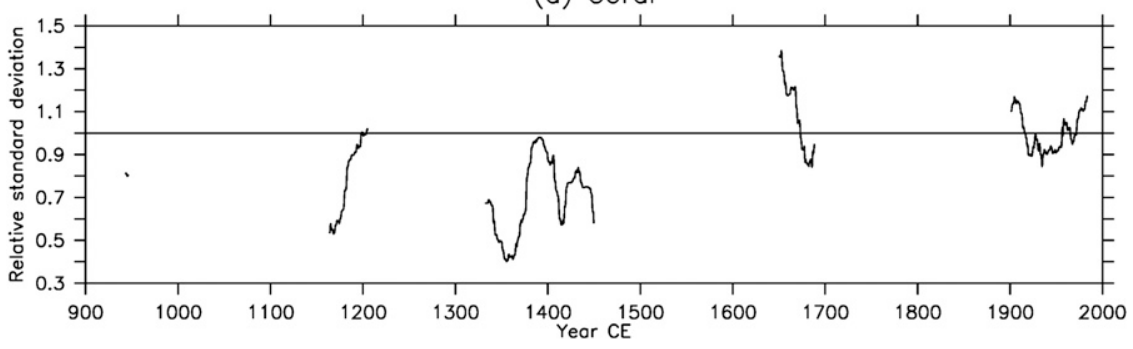

(b) Pre-industrial control

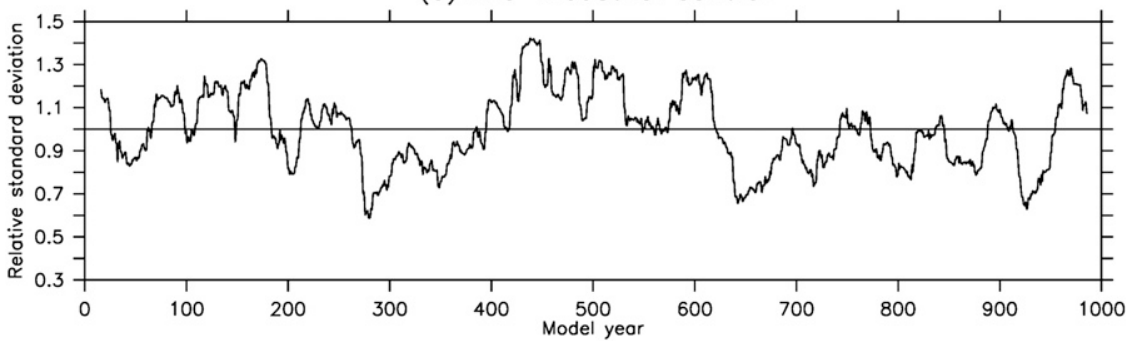

(c) Orbital-Greenhouse-Solar-Volcanic

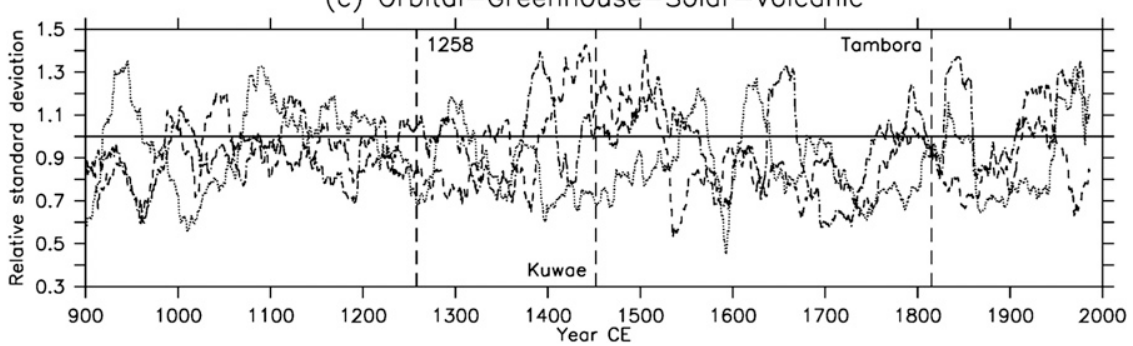

FIG. 7. The 30 -yr running standard deviation in (a) coral $\delta^{18} \mathrm{O}$ at Palmyra Island $\left(6^{\circ} \mathrm{N}\right.$, $162^{\circ} \mathrm{W}$ ), (b) pseudocoral derived from a preindustrial control simulation, and (c) pseudocoral derived from the three members of ensemble OGSV. A 2-7-yr bandpass filter is applied to the data before calculating the standard deviation. The preindustrial control pseudocoral is expressed relative to the average value of the 30-yr running standard deviation for the control simulation. All other values are expressed relative to the average value of the 30 -yr running standard deviation over the period 1886-1975 CE. Vertical dashed lines indicate the volcanic eruptions of 1258 CE (unknown location), 1452 CE (Kuwae), and 1815 CE (Tambora).

the amplitude of ENSO variability over this period. Thus, while we are able to detect both natural and anthropogenic influences on the mean state of the central Pacific, we are not able to detect any influence of these same forcings on the simulated ENSO. This conclusion is in agreement with the multimodel analysis of Stevenson (2012), who finds significant changes to the tropical Pacific mean state but no predictable influence of anthropogenic climate change on ENSO amplitude.

Overall, these results are consistent with those of EmileGeay et al. (2007), who, using the highly simplified Zebiak-Cane model, find no evidence that a $0.05 \%$ change in solar irradiance has any impact on ENSO variability. Such perturbations are similar in magnitude to the changes in solar irradiance applied in this study (Steinhilber et al. 2009). While Mann et al. (2005) and Emile-Geay et al. (2007), using the same model, find that larger changes in solar irradiance can influence ENSO variability via changes in the background state of the tropical Pacific, such changes are not supported by current reconstructions of solar irradiance over the past 1500 years (Schmidt et al. 2012). The lack of any detectable volcanic influence on ENSO variability is also consistent with other modeling studies, which find that volcanoes alter the probabilities of El Niño and La Niña events occurring in the immediate aftermath of an eruption but otherwise have no lasting impact (Mann et al. 2005; Emile-Geay et al. 2008; McGregor and Timmermann 2011).

\section{d. Twentieth-century climate change}

In section $4 b$, we noted the difference in magnitude between the responses of the coral $\delta^{18} \mathrm{O}$ record and the pseudocorals during the late twentieth century. One possible explanation for this discrepancy is that anthropogenic 
TABLE 6. Regression coefficients for the fit of the simulated monthly SST anomaly in the Niño- 3.4 region $\left(5^{\circ} \mathrm{S}-5^{\circ} \mathrm{N}, 170^{\circ}-120^{\circ} \mathrm{W}\right)$ onto the simulated monthly anomalies in SST, SSS, $P$, and $E$ at Palmyra Island $\left(6^{\circ} \mathrm{N}, 162^{\circ} \mathrm{W}\right)$. The values are derived from each member of ensemble OGSV for the periods (a) 501-1850 CE and (b) 1851-2000 CE. 95\% confidence intervals are calculated using bootstrapping (Wilks 2011).

\begin{tabular}{ccccc}
\hline \hline & \multicolumn{4}{c}{ Regression coefficient } \\
\cline { 2 - 5 } Ensemble member & SST $\left(\mathrm{K} \mathrm{K}^{-1}\right)$ & SSS $\left(\mathrm{K} \mathrm{psu}^{-1}\right)$ & $P\left(\mathrm{~K} \mathrm{~mm}^{-1}\right.$ day $)$ & \\
\hline & & (a) $501-1850 \mathrm{CE}$ & \\
1 & $+0.725 \pm 0.013$ & $-0.516 \pm 0.051$ & $+0.024 \pm 0.002$ & $+0.239 \pm 0.013$ \\
2 & $+0.742 \pm 0.012$ & $-0.607 \pm 0.053$ & $+0.024 \pm 0.002$ & $+0.237 \pm 0.012$ \\
3 & $+0.744 \pm 0.012$ & $-0.441 \pm 0.048$ & $+0.028 \pm 0.002$ & $+0.256 \pm 0.012$ \\
& & (b) $1851-2000 \mathrm{CE}$ & & $+0.216 \pm 0.033$ \\
2 & $+0.795 \pm 0.033$ & $-0.517 \pm 0.142$ & $+0.030 \pm 0.006$ & $+0.234 \pm 0.034$ \\
3 & $+0.815 \pm 0.035$ & $-0.435 \pm 0.125$ & $+0.025 \pm 0.006$ & $+0.228 \pm 0.034$ \\
\hline
\end{tabular}

climate change might have impacted the relationship between ENSO and the local climate at Palmyra Island. The model simulations allow us to test the stability of this relationship over time, with particular regard to changes in the climate induced by natural and anthropogenic forcings. The previous process of deriving a pseudocoral indicator is therefore repeated but this time using the three members of ensemble OGSV instead of the preindustrial control simulation. The regression is performed separately for the preindustrial (501-1850 CE) and industrial (1851-2000 CE) periods of each simulation. Table 6 shows the regression coefficients that are obtained.

The results for the preindustrial period (Table 6a) show slightly larger values for the SST regression coefficient and smaller values for the SSS regression coefficient than those obtained from the control simulation. These differences are significant at the $95 \%$ confidence level in most cases, indicating a different relationship between ENSO and the local climate over the preindustrial period once natural forcings are taken into account. There are also statistically significant differences between the SSS coefficients derived from ensemble members 2 and 3, suggesting low-frequency modulation to the relationship operating on time scales even longer than the 1350 -yr period used to perform the regression.

The results for the industrial period (Table $6 \mathrm{~b}$ ) are different again. The values for the SST regression coefficient are larger than those obtained for either the control simulation or the preindustrial period, with the differences being significant at the $95 \%$ confidence level for two of the three ensemble members. This indicates that anthropogenic forcing, in addition to natural forcings, influences the relationship between ENSO and the local climate. However, although many of the differences in the regression coefficients are statistically significant, they have only a modest impact upon the values of the pseudocoral indicators. For example, two pseudocoral time series derived from ensemble member two, one using Eq. (2) and the other using the coefficients shown in Table $6 \mathrm{~b}$, are found to have $99.1 \%$ shared variance over the industrial period (not shown). Thus the discrepancy between the coral $\delta^{18} \mathrm{O}$ record and the pseudocorals during the late twentieth century is not due to changing relationships within the climate system or at least not as simulated by the model.

Instead, the discrepancy could be due to deficiencies in the model physics, or it could indicate that the changes in the local climate arose at least in part through natural variability (e.g., McPhaden et al. 2011). A further possibility is that changes in the remote climate, such as a change in the oceanic circulation or a change in the source area or trajectory of the moisture that forms local precipitation, have influenced $\operatorname{coral} \delta^{18} \mathrm{O}$ at Palmyra Island (Nurhati et al. 2009, 2011). To fully explore these possibilities within a modeling framework would require not only a climate model that incorporates a representation of the global distribution of $\delta^{18} \mathrm{O}$ but also a process model that describes the incorporation of the climatic signal into coral $\delta^{18} \mathrm{O}$ at the study site.

\section{Discussion and conclusions}

The CSIRO Mk3L climate system model, driven by reconstructed changes in natural and anthropogenic forcings, has been used to simulate changes in the global climate over the past 1500 years. By comparing the simulations with multiple proxy records, we are able to study the role of external forcings in driving the global climate over this period. We apply both the inverse and forward approaches to paleoclimate data-model comparison, and we are able to identify sources of uncertainty.

The model simulations are first compared with the Mann et al. (2008) multiproxy reconstructions of NH and $\mathrm{SH}$ temperature. A weak but detectable volcanic signal is identified in $\mathrm{NH}$ temperature over the past 1500 years, 
although this conclusion is found to be sensitive to possible orbitally induced biases in the reconstruction. In contrast, strong and robust solar and volcanic signals are identified in SH temperature. During the post-1850 CE industrial period, increasing concentrations of anthropogenic greenhouse gases dominate over natural forcings in both hemispheres.

The model simulations are then compared with a coral $\delta^{18} \mathrm{O}$ record from the central Pacific Ocean. We employ a simple forward model, constructing a pseudocoral indicator from simulated anomalies in sea surface temperature, sea surface salinity, precipitation, and evaporation. The pseudocorals demonstrate statistically significant roles of solar irradiance, volcanic eruptions, and greenhouse gases in driving changes in the mean state of the central Pacific over the past 1100 years. The dynamical response of the model on decadal time scales appears to be characterized by a Weaker Walker response to changing anthropogenic greenhouse gases. However, there is no evidence of any systematic influence of natural or anthropogenic forcings on the amplitude of the simulated ENSO variability. The results obtained using our modeling framework are therefore consistent with the conclusion of Cobb et al. (2003) that changes in ENSO variability are uncorrelated with either external forcings or changes in the mean state. This supports the notion that ENSO is a system where variability arises from internal dynamics, independent of external forcing.

By employing the inverse and forward approaches side-by-side within the same study, we have been able to identify sources of uncertainty that limit our ability to draw definitive conclusions about the drivers of past climate. Many of these are common to the two approaches: where there are discrepancies between the model simulations and the proxy data, possible sources of uncertainty include deficiencies in the model physics, errors in the forcing datasets used to drive the model, and internal climate variability. In the case of the inverse approach, additional uncertainty is contributed by the inevitable uncertainties introduced by techniques for multiproxy reconstruction. One example of this is the possibility of seasonal and geographical biases in the response of proxy networks, which we conclude may cause temperature reconstructions to systematically overestimate the magnitude of the long-term preindustrial cooling trend. Both the inverse and pseudocoral approaches also rely upon the assumption of stationarity in proxy climate relationships. However, the model simulations demonstrate natural and anthropogenic influences on the relationship between ENSO and the climate of Palmyra Island, which suggests that the relationships between paleoclimate proxies and climatic variables may be nonstationary over time.
Alternative approaches to paleoclimate data-model comparison are required in order to reduce uncertainty and hence improve our understanding of the drivers of past climates. Forward modeling would avoid the uncertainties inherent in techniques for paleoclimate reconstruction. However, it would not eliminate any of the other sources of uncertainty encountered here, and it would introduce an additional source of uncertainty associated with the representation of processes within the forward models themselves. Data assimilation also has potential. By constraining model simulations to follow reconstructions, it would reduce the uncertainties associated with model physics, external forcings, and internal climate variability. However, as an extension of the inverse approach, it is subject to the same limitation of the assumption of stationarity. A combination of forward modeling and data assimilation, which would allow proxy data to be directly assimilated into a climate modeling framework, might therefore be optimal. However, we emphasize that the development of a comprehensive forward modeling capability that encompasses all commonly used proxies may not exist for many years.

In the interim, this analysis indicates that climate modeling can play a potentially critical role in paleoclimate reconstruction, with the models being used to test the underlying assumption of stationarity (Ackerley et al. 2013). While a forward modeling capability would be required to test the stability of proxy climate relationships, even conventional climate models could be used to test the stability of teleconnections over time. In this sense, climate modeling has a role to play not just within the context of paleoclimate data-model comparison but even within the wider context of the interpretation of the proxies themselves. Confidence in the interpretation of a proxy in terms of larger-scale climatic variables would be enhanced when climate models are able to reproduce observed teleconnections within the climate system and when the models further demonstrate that these relationships are stable over time.

In conclusion, we suggest three future research priorities in order to progressively reduce uncertainty in paleoclimate data-model comparison:

- the development of better reconstructions of past climatic forcings;

- the use of climate modeling to underpin current techniques for paleoclimate reconstruction, with the models being used to test the stability of relationships within the climate system; and

- the ongoing development of alternative approaches to paleoclimate data-model comparison, particularly forward modeling and data assimilation. 
Finally, we note that this study has been based on a single climate model, a single set of hemispheric temperature reconstructions, and a single coral $\delta^{18} \mathrm{O}$ record. The conclusions regarding drivers of past climate should therefore be regarded as preliminary. Possible sources of bias in the results presented here include deficiencies in the physics of the model and its coupled behavior, deficiencies in the forcing datasets applied to the model, the omission of anthropogenic forcings other than greenhouse gases, and deficiencies in the reconstructions and $\delta^{18} \mathrm{O}$ record. The analysis performed here should be repeated using alternative models, forcing datasets, and records of past climate in order to assess the sensitivity of the conclusions to the specific tools used.

Acknowledgments. This research was supported under the Australian Research Council's Discovery Projects and Linkage Projects funding schemes (Projects DP1092945 and LP0990151). This work was also supported by an award from the Australian Government Department of Climate Change and Energy Efficiency and by an award under the Merit Allocation Scheme on the NCI National Facility at the Australian National University. HVM is supported by an AINSE Research Fellowship. The authors wish to acknowledge use of the Ferret program for analysis and graphics in this paper (http://ferret.pmel.noaa.gov/Ferret/). The anthropogenic greenhouse gas concentrations of MacFarling Meure et al. (2006) were supplied by David Etheridge. We thank NOAA for supporting the production of this special issue of Journal of Climate. Comments by David Frank, Andrew Lorrey, and three anonymous reviewers have greatly improved this manuscript.

\section{REFERENCES}

Ackerley, D., A. Lorrey, J. Renwick, S. J. Phipps, S. Wagner, and A. Fowler, 2013: High-resolution modelling of mid-Holocene New Zealand climate 6000 yr BP. Holocene, doi:10.1177/ 0959683613484612.

Allen, M. R., and P. A. Stott, 2003: Estimating signal amplitudes in optimal fingerprinting. Part I: Theory. Climate Dyn., 21, 477491, doi:10.1007/s00382-003-0313-9.

Ammann, C. M., F. Joos, D. S. Schimel, B. L. Otto-Bliesner, and R. A. Tomas, 2007: Solar influence on climate during the past millennium: Results from transient simulations with the NCAR Climate System Model. Proc. Natl. Acad. Sci. USA, 104, 3713-3718, doi:10.1073/pnas.0605064103.

Baker, A., C. Bradley, S. J. Phipps, M. Fischer, I. J. Fairchild, L. Fuller, C. Spötl, and C. Azcurra, 2012: Millennial-length forward models and pseudoproxies of stalagmite $\delta^{18} \mathrm{O}$ : An example from NW Scotland. Climate Past, 8, 1153-1167, doi:10.5194/cp-8-1153-2012.

Bartlein, P. J., and Coauthors, 1998: Paleoclimate simulations for North America over the past 21,000 years: Features of the simulated climate and comparisons with paleoenvironmental data. Quat. Sci. Rev., 17, 549-585.
Berger, A. L., 1978: Long-term variations of daily insolation and Quaternary climatic changes. J. Atmos. Sci., 35, 2362-2367.

Berkelhammer, M., and L. D. Stott, 2009: Modeled and observed intra-ring $\delta^{18} \mathrm{O}$ cycles within late Holocene bristlecone pine tree samples. Chem. Geol., 264, 13-23, doi:10.1016/ j.chemgeo.2009.02.010.

Braconnot, P., and Coauthors, 2007a: Results of PMIP2 coupled simulations of the Mid-Holocene and Last Glacial MaximumPart 1: Experiments and large-scale features. Climate Past, 3, 261-277.

— , and Coauthors, 2007b: Results of PMIP2 coupled simulations of the Mid-Holocene and Last Glacial MaximumPart 2: Feedbacks with emphasis on the location of the ITCZ and mid- and high latitudes heat budget. Climate Past, 3, 279-296.

Brohan, P., J. J. Kennedy, I. Harris, S. F. B. Tett, and P. D. Jones, 2006: Uncertainty estimates in regional and global observed temperature changes: A new data set from 1850. J. Geophys. Res., 111, D12106, doi:10.1029/2005JD006548.

Brown, J., I. Simmonds, and D. Noone, 2006: Modeling $\delta^{18} \mathrm{O}$ in tropical precipitation and the surface ocean for presentday climate. J. Geophys. Res., 111, D05105, doi:10.1029/ 2004JD005611.

—, A. W. Tudhope, M. Collins, and H. V. McGregor, 2008: MidHolocene ENSO: Issues in quantitative model-proxy data comparisons. Paleoceanography, 23, PA3202, doi:10.1029/ 2007PA001512.

Claussen, M., and Coauthors, 2002: Earth system models of intermediate complexity: Closing the gap in the spectrum of climate system models. Climate Dyn., 18, 579-586.

Clement, A. C., R. Seager, M. A. Cane, and S. E. Zebiak, 1996: An ocean dynamical thermostat. J. Climate, 9, 2190-2196.

Cobb, K. M., C. D. Charles, H. Cheng, and R. L. Edwards, 2003: El Niño/Southern Oscillation and tropical Pacific climate during the last millennium. Nature, 424, 271-276.

Cole, J. E., and R. G. Fairbanks, 1990: The Southern Oscillation recorded in the $\delta^{18} \mathrm{O}$ of corals from Tarawa Atoll. Paleoceanography, 5, 669-683.

Corrège, T., 2006: Sea surface temperature and salinity reconstruction from coral geochemical tracers. Palaeogeogr. Palaeoclimatol. Palaeoecol., 232, 408-428.

Crowley, T. J., 2000: Causes of climate change over the past 1000 years. Science, 289, 270-277.

Diaz, H. F., R. Trigo, M. K. Hughes, M. E. Mann, E. Xoplaki, and D. Barriopedro, 2011: Spatial and temporal characteristics of climate in medieval times revisited. Bull. Amer. Meteor. Soc., 92, 1487-1500.

DiNezio, P. N., A. Clement, G. A. Vecchi, B. Soden, A. J. Broccoli, B. L. Otto-Bliesner, and P. Braconnot, 2011: The response of the Walker circulation to Last Glacial Maximum forcing: Implications for detection in proxies. Paleoceanography, 26, PA3217, doi:10.1029/2010PA002083.

Ebisuzaki, W., 1997: A method to estimate the statistical significance of a correlation when the data are serially correlated. J. Climate, 10, 2147-2153.

Emile-Geay, J., M. Cane, R. Seager, A. Kaplan, and P. Almasi, 2007: El Niño as a mediator of the solar influence on climate. Paleoceanography, 22, PA3210, doi:10.1029/2006PA001304.

- - R. Seager, M. A. Cane, E. R. Cook, and G. H. Haug, 2008: Volcanoes and ENSO over the past millennium. J. Climate, 21, 3134-3148.

Epstein, S., R. Buchsbaum, H. A. Lowenstam, and H. C. Urey, 1953: Revised carbonate-water isotopic temperature scale. Geol. Soc. Amer. Bull., 64, 1315-1326. 
Esper, J., and Coauthors, 2012: Orbital forcing of tree-ring data. Nat. Climate Change, 2, 862-866, doi:10.1038/NCLIMATE1589.

Evans, M. N., 2007: Toward forward modeling for paleoclimatic proxy signal calibration: A case study with oxygen isotopic composition of tropical woods. Geochem. Geophys. Geosyst., 8, Q07008, doi:10.1029/2006GC001406.

_ B. K. Reichert, A. Kaplan, K. J. Anchukaitis, E. A. Vaganov, M. K. Hughes, and M. A. Cane, 2006: A forward modeling approach to paleoclimatic interpretation of tree-ring data. J. Geophys. Res., 111, G03008, doi:10.1029/2006JG000166.

Fairbanks, R. G., M. N. Evans, J. L. Rubenstone, R. A. Mortlock, K. Broad, M. D. Moore, and C. D. Charles, 1997: Evaluating climate indices and their geochemical proxies measured in corals. Coral Reefs, 16 (Suppl.), S93-S100.

Fernández-Donado, L., and Coauthors, 2013: Large-scale temperature response to external forcing in simulations and reconstructions of the last millennium. Climate Past, 9, 393-421, doi:10.5194/cp-9-393-2013.

Fischer, M. J., and P. C. Treble, 2008: Calibrating climate- $\delta{ }^{18} \mathrm{O}$ regression models for the interpretation of high-resolution speleothem $\delta^{18} \mathrm{O}$ time series. J. Geophys. Res., 113, D17103, doi:10.1029/2007JD009694.

Fowler, A. M., G. Boswijk, A. M. Lorrey, J. Gergis, M. Pirie, S. P. J. McCloskey, J. G. Palmer, and J. Wunder, 2012: Multicentennial tree-ring record of ENSO-related activity in New Zealand. Nat. Climate Change, 2, 172-176, doi:10.1038/ NCLIMATE1374.

Frank, D. C., J. Esper, C. C. Raible, U. Büntgen, V. Trouet, B. Stocker, and F. Joos, 2010: Ensemble reconstruction constraints on the global carbon cycle sensitivity to climate. $\mathrm{Na}$ ture, 463, 527-532, doi:10.1038/nature08769.

Free, M., and A. Robock, 1999: Global warming in the context of the Little Ice Age. J. Geophys. Res., 104 (D16), 19 057-19070.

Gagan, M. K., L. K. Ayliffe, J. W. Beck, J. E. Cole, E. R. M. Druffel, R. B. Dunbar, and D. P. Schrag, 2000: New views of tropical paleoclimates from corals. Quat. Sci. Rev., 19, 45-64.

Gao, C., A. Robock, and C. Ammann, 2008: Volcanic forcing of climate over the past 1500 years: An improved ice-core based index for climate models. J. Geophys. Res., 113, D23111, doi:10.1029/2008JD010239.

Gergis, J., and Coauthors, 2012: On the long-term context of the 1997-2009 'Big Dry' in south-eastern Australia: Insights from a 206-year multi-proxy rainfall reconstruction. Climatic Change, 111, 923-944, doi:10.1007/s10584-011-0263-x.

Goosse, H., E. Crespin, S. Dubinkina, M.-F. Loutre, M. E. Mann, H. Renssen, Y. Sallaz-Damaz, and D. Shindell, 2012: The role of forcing and internal dynamics in explaining the "Medieval Climate Anomaly." Climate Dyn., 39, 2847-2866, doi:10.1007/ s00382-012-1297-0.

Graham, N. E., C. M. Ammann, D. Fleitmann, K. M. Cobb, and J. Luterbacher, 2011: Support for global climate reorganization during the "Medieval Climate Anomaly." Climate Dyn., 37, 1217-1245, doi:10.1007/s00382-010-0914-z.

Hargreaves, J. C., and J. D. Annan, 2009: On the importance of paleoclimate modelling for improving predictions of future climate change. Climate Past, 5, 803-814.

Hegerl, G. C., T. J. Crowley, S. K. Baum, K.-Y. Kim, and W. T. Hyde, 2003: Detection of volcanic, solar and greenhouse gas signals in paleo-reconstructions of Northern Hemispheric temperature. Geophys. Res. Lett., 30, 1242, doi:10.1029/ 2002 GL016635.

,,-- M. Allen, W. T. Hyde, H. N. Pollack, J. Smerdon, and E. Zorita, 2007a: Detection of human influence on a new, validated 1500-year temperature reconstruction. J. Climate, 20, 650-666.

- and Coauthors, 2007b: Understanding and attributing climate change. Climate Change 2007: The Physical Science Basis, S. Solomon et al., Eds., Cambridge University Press, 663-745.

—, J. Luterbacher, F. González-Rouco, S. F. B. Tett, T. Crowley, and E. Xoplaki, 2011: Influence of human and natural forcing on European seasonal temperatures. Nat. Geosci., 4, 99-103, doi:10.1038/NGEO1057.

Held, I. M., and B. J. Soden, 2006: Robust responses of the hydrological cycle to global warming. J. Climate, 19, 5686-5699.

Jansen, E., and Coauthors, 2007: Palaeoclimate. Climate Change 2007: The Physical Science Basis, S. Solomon et al., Eds., Cambridge University Press, 433-497.

Jin, F.-F., J. D. Neelin, and M. Ghil, 1994: El Niño on the devil's staircase: Annual subharmonic steps to chaos. Science, 264, 70-72.

Jones, P. D., and Coauthors, 2009: High-resolution palaeoclimatology of the last millennium: A review of current status and future prospects. Holocene, 19, 3-49, doi:10.1177/0959683608098952.

Juillet-Leclerc, A., and G. Schmidt, 2001: A calibration of the oxygen isotope paleothermometer of coral aragonite from porites. Geophys. Res. Lett., 28, 4135-4138.

Jungclaus, J. H., and Coauthors, 2010: Climate and carbon-cycle variability over the last millennium. Climate Past, 6, 723-737, doi:10.5194/cp-6-723-2010.

Kaufman, D. S., and Coauthors, 2009: Recent warming reverses long-term Arctic cooling. Science, 325, 1236-1239, doi:10.1126/ science.1173983.

Liu, Z., J. Kutzbach, and L. Wu, 2000: Modeling climate shift of El Niño variability in the Holocene. Geophys. Res. Lett., 27, 2265-2268.

MacFarling Meure, C., D. Etheridge, C. Trudinger, P. Steele, R. Langenfelds, T. van Ommen, A. Smith, and J. Elkins, 2006: Law Dome $\mathrm{CO}_{2}, \mathrm{CH}_{4}$ and $\mathrm{N}_{2} \mathrm{O}$ ice core records extended to 2000 years BP. Geophys. Res. Lett., 33, L14810, doi:10.1029/ 2006GL026152.

Mann, M. E., M. A. Cane, S. E. Zebiak, and A. Clement, 2005: Volcanic and solar forcing of the tropical Pacific over the past 1000 years. J. Climate, 18, 447-456.

Z. Zhang, M. K. Hughes, R. S. Bradley, S. K. Miller, S. Rutherford, and F. Ni, 2008: Proxy-based reconstructions of hemispheric and global surface temperature variations over the past two millennia. Proc. Natl. Acad. Sci. USA, 105, 13 252-13 257, doi:10.1073/pnas.0805721105.

, and Coauthors, 2009: Global signatures and dynamical origins of the Little Ice Age and Medieval Climate Anomaly. Science, 326, 1256-1260, doi:10.1126/science.1177303.

, J. D. Fuentes, and S. Rutherford, 2012: Underestimation of volcanic cooling in tree-ring-based reconstructions of hemispheric temperatures. Nat. Geosci., 5, 202-205, doi:10.1038/ NGEO1394.

McGregor, S., and A. Timmermann, 2011: The effects of explosive tropical volcanism on ENSO. J. Climate, 24, 2178-2191.

McPhaden, M. J., T. Lee, and D. McClurg, 2011: El Niño and its relationship to changing background conditions in the tropical Pacific Ocean. Geophys. Res. Lett., 38, L15709, doi:10.1029/ 2011 GL048275.

Miller, G. H., and Coauthors, 2012: Abrupt onset of the Little Ice Age triggered by volcanism and sustained by sea-ice/ocean feedbacks. Geophys. Res. Lett., 39, L02708, doi:10.1029/ 2011GL050168.

Moy, C. M., G. O. Seltzer, D. T. Rodbell, and D. M. Anderson, 2002: Variability of El Niño/Southern Oscillation activity at 
millennial timescales during the Holocene epoch. Nature, 420, $162-165$.

Nurhati, I. S., K. M. Cobb, C. D. Charles, and R. B. Dunbar, 2009: Late 20th century warming and freshening in the central tropical Pacific. Geophys. Res. Lett., 36, L21606, doi:10.1029/ 2009GL040270.

— - - and E. D. Lorenzo, 2011: Decadal-scale SST and salinity variations in the central tropical Pacific: Signatures of natural and anthropogenic climate change. J. Climate, 24, 3294-3308.

Otto-Bliesner, B. L., E. C. Brady, G. Clauzet, R. Tomas, S. Levis, and Z. Kothavala, 2006: Last Glacial Maximum and Holocene climate in CCSM3. J. Climate, 19, 2526-2544.

Phipps, S. J., and J. N. Brown, 2010: Understanding ENSO dynamics through the exploration of past climates. IOP Conf. Ser. Earth Environ. Sci., 9, 012010, doi:10.1088/1755-1315/9/1/ 012010.

—, L. D. Rotstayn, H. B. Gordon, J. L. Roberts, A. C. Hirst, and W. F. Budd, 2011: The CSIRO Mk3L climate system model version 1.0-Part 1: Description and evaluation. Geosci. Model Dev., 4, 483-509, doi:10.5194/gmd-4-483-2011.

$-,-\longrightarrow,-,-\longrightarrow$, and,- 2012 : The CSIRO Mk3L climate system model version 1.0-Part 2: Response to external forcings. Geosci. Model Dev., 5, 649-682, doi:10.5194/ gmd-5-649-2012.

Plummer, C. T., and Coauthors, 2012: An independently dated 2000-yr volcanic record from Law Dome, East Antarctica, including a new perspective on the dating of the c. 1450s eruption of Kuwae, Vanuatu. Climate Past, 8, 1929-1940, doi:10.5194/cp-8-1929-2012.

Rayner, N. A., P. Brohan, D. E. Parker, C. K. Folland, J. J. Kennedy, M. Vanicek, T. J. Ansell, and S. F. B. Tett, 2006: Improved analyses of changes and uncertainties in sea surface temperature measured in situ since the mid-nineteenth century: The HadSST2 dataset. J. Climate, 19, 446-469.

Robock, A., 2005: Cooling following large volcanic eruptions corrected for the effect of diffuse radiation on tree rings. Geophys. Res. Lett., 32, L06702, doi:10.1029/2004GL022116.

Rohling, E. J., and G. R. Bigg, 1998: Paleosalinity and $\delta^{18} \mathrm{O}$ : A critical assessment. J. Geophys. Res., 103 (C1), 1307-1318.

Santoso, A., W. Cai, M. H. England, and S. J. Phipps, 2011: The role of the Indonesian Throughflow on ENSO dynamics in a coupled climate model. J. Climate, 24, 585-601.

Schmidt, G. A., and Coauthors, 2012: Climate forcing reconstructions for use in PMIP simulations of the last millennium (v1.1). Geosci. Model Dev., 5, 185-191, doi:10.5194/ gmd-5-185-2012.

Schneider, T., 2001: Analysis of incomplete climate data: Estimation of mean values and covariance matrices and imputation of missing values. J. Climate, 14, 853-871.

Shindell, D. T., G. A. Schmidt, M. E. Mann, D. Rind, and A. Waple, 2001: Solar forcing of regional climate change during the Maunder Minimum. Science, 294, 2149-2152.

Steinhilber, F., J. Beer, and C. Fröhlich, 2009: Total solar irradiance during the Holocene. Geophys. Res. Lett., 36, L19704, doi:10.1029/2009GL040142.

— - and Coauthors, 2012: 9,400 years of cosmic radiation and solar activity from ice cores and tree rings. Proc. Natl. Acad. Sci. USA, 109, 5967-5971, doi:10.1073/pnas.1118965109.

Stevenson, S. L., 2012: Significant changes to ENSO strength and impacts in the twenty-first century: Results from CMIP5. Geophys. Res. Lett., 39, L17703, doi:10.1029/2012GL052759.
- B. Fox-Kemper, M. Jochum, R. Neale, C. Deser, and G. Meehl, 2012: Will there be a significant change to El Niño in the twenty-first century? J. Climate, 25, 2129-2145.

Stott, P. A., M. R. Allen, and G. S. Jones, 2003: Estimating signal amplitudes in optimal fingerprinting. Part II: Application to general circulation models. Climate Dyn., 21, 493-500, doi:10.1007/s00382-003-0314-8.

Thompson, D. M., T. R. Ault, M. N. Evans, J. E. Cole, and J. EmileGeay, 2011: Comparison of observed and simulated tropical climate trends using a forward model of coral $\delta^{18} \mathrm{O}$. Geophys. Res. Lett., 38, L14706, doi:10.1029/2011GL048224.

Thompson, D. W. J., J. M. Wallace, P. D. Jones, and J. J. Kennedy, 2009: Identifying signatures of natural climate variability in time series of global-mean surface temperature: Methodology and insights. J. Climate, 22, 6120-6141.

Timmreck, C., S. J. Lorenz, T. J. Crowley, S. Kinne, T. J. Raddatz, M. A. Thomas, and J. H. Jungclaus, 2009: Limited temperature response to the very large AD 1258 volcanic eruption. Geophys. Res. Lett., 36, L21708, doi:10.1029/2009GL040083.

Tindall, J. C., P. J. Valdes, and L. C. Sime, 2009: Stable water isotopes in HadCM3: Isotopic signature of El Niño-Southern Oscillation and the tropical amount effect. J. Geophys. Res., 114, D04111, doi:10.1029/2008JD010825.

Tolwinski-Ward, S. E., M. N. Evans, M. K. Hughes, and K. J. Anchukaitis, 2011: An efficient forward model of the climate controls on interannual variation in tree-ring width. Climate Dyn., 36, 2419-2439, doi:10.1007/s00382-010-0945-5.

Trenberth, K. E., and Coauthors, 2007: Observations: Surface and atmospheric climate change. Climate Change 2007: The Physical Science Basis, S. Solomon et al., Eds., Cambridge University Press, 235-336.

Tudhope, A. W., and Coauthors, 2001: Variability in the El NiñoSouthern Oscillation through a glacial-interglacial cycle. Science, 291, 1511-1517.

Tziperman, E., L. Stone, M. A. Cane, and H. Jarosh, 1994: El Niño chaos: Overlapping of resonances between the seasonal cycle and the Pacific Ocean-atmosphere oscillator. Science, 264, 72-74.

van Ommen, T. D., and V. Morgan, 2010: Snowfall increase in coastal East Antarctica linked with southwest Western Australian drought. Nat. Geosci., 3, 267-272, doi:10.1038/NGEO761.

Vecchi, G. A., B. J. Soden, A. T. Wittenberg, I. M. Held, A. Leetma, and M. J. Harrison, 2006: Weakening of tropical Pacific atmospheric circulation due to anthropogenic forcing. Nature, 441, 73-76, doi:10.1038/nature04744.

Wahl, E. R., and J. E. Smerdon, 2012: Comparative performance of paleoclimate field and index reconstructions derived from climate proxies and noise-only predictors. Geophys. Res. Lett., 39, L06703, doi:10.1029/2012GL051086.

Weber, J. N., and P. M. J. Woodhead, 1972: Temperature dependence of oxygen-18 concentration in reef coral carbonates. J. Geophys. Res., 77 (3), 463-473.

Wilks, D. S., 2011: Statistical Methods in the Atmospheric Sciences. 3rd ed. Academic Press, $676 \mathrm{pp}$

Wilson, R., E. Cook, R. D'Arrigo, N. Riedwyl, M. N. Evans, A. Tudhope, and R. Allan, 2010: Reconstructing ENSO: The influence of method, proxy data, climate forcing and teleconnections. J. Quat. Sci., 25, 62-78, doi:10.1002/jqs.1297.

Zheng, W., P. Braconnot, E. Guilyardi, U. Merkel, and Y. Yu, 2008: ENSO at 6ka and 21ka from ocean-atmosphere coupled model simulations. Climate Dyn., 30, 745-762, doi:10.1007/ s00382-007-0320-3. 